\title{
Model simulations of the chemical and aerosol microphysical evolution of the Sarychev Peak 2009 eruption cloud compared to in situ and satellite observations
}

\author{
Thibaut Lurton $^{1, \mathrm{a}}$, Fabrice Jégou ${ }^{1}$, Gwenaël Berthet ${ }^{1}$, Jean-Baptiste Renard ${ }^{1}$, Lieven Clarisse ${ }^{2}$, Anja Schmidt ${ }^{3,4}$, \\ Colette Brogniez $^{5}$, and Tjarda J. Roberts ${ }^{1}$ \\ ${ }^{1}$ Laboratoire de Physique et Chimie de l'Environnement et de l'Espace (LPC2E), Université d'Orléans, \\ CNRS UMR7328, Orléans, France \\ ${ }^{2}$ Université Libre de Bruxelles (ULB), Atmospheric Spectroscopy, Service de Chimie Quantique et \\ Photophysique, Brussels, Belgium \\ ${ }^{3}$ Department of Chemistry, University of Cambridge, Lensfield Road, Cambridge CB2 1EW, UK \\ ${ }^{4}$ Department of Geography, University of Cambridge, Downing Place, Cambridge CB2 3EN, UK \\ ${ }^{5}$ Laboratoire d'Optique Atmosphérique, Université de Lille, Sciences et Technologies, \\ Villeneuve-d'Ascq, France \\ ${ }^{a}$ now at: Institut Pierre-Simon Laplace (IPSL), Sorbonne Université, CNRS FR636, Paris, France
}

Correspondence: Thibaut Lurton (thibaut.lurton@ipsl.fr)

Received: 17 September 2017 - Discussion started: 16 October 2017

Revised: 24 January 2018 - Accepted: 26 January 2018 - Published: 6 March 2018

\begin{abstract}
Volcanic eruptions impact climate through the injection of sulfur dioxide $\left(\mathrm{SO}_{2}\right)$, which is oxidized to form sulfuric acid aerosol particles that can enhance the stratospheric aerosol optical depth (SAOD). Besides largemagnitude eruptions, moderate-magnitude eruptions such as Kasatochi in 2008 and Sarychev Peak in 2009 can have a significant impact on stratospheric aerosol and hence climate. However, uncertainties remain in quantifying the atmospheric and climatic impacts of the 2009 Sarychev Peak eruption due to limitations in previous model representations of volcanic aerosol microphysics and particle size, whilst biases have been identified in satellite estimates of post-eruption SAOD. In addition, the 2009 Sarychev Peak eruption co-injected hydrogen chloride $(\mathrm{HCl})$ alongside $\mathrm{SO}_{2}$, whose potential stratospheric chemistry impacts have not been investigated to date. We present a study of the stratospheric $\mathrm{SO}_{2}$-particle- $\mathrm{HCl}$ processing and impacts following Sarychev Peak eruption, using the Community Earth System Model version 1.0 (CESM1) Whole Atmosphere Community Climate Model (WACCM) - Community Aerosol and Radiation Model for Atmospheres (CARMA) sectional aerosol microphysics model (with no a priori assumption on particle size). The Sarychev Peak 2009 eruption injected 0.9 Tg
\end{abstract}

of $\mathrm{SO}_{2}$ into the upper troposphere and lower stratosphere (UTLS), enhancing the aerosol load in the Northern Hemisphere. The post-eruption evolution of the volcanic $\mathrm{SO}_{2}$ in space and time are well reproduced by the model when compared to Infrared Atmospheric Sounding Interferometer (IASI) satellite data. Co-injection of $27 \mathrm{Gg} \mathrm{HCl}$ causes a lengthening of the $\mathrm{SO}_{2}$ lifetime and a slight delay in the formation of aerosols, and acts to enhance the destruction of stratospheric ozone and mono-nitrogen oxides $\left(\mathrm{NO}_{x}\right)$ compared to the simulation with volcanic $\mathrm{SO}_{2}$ only. We therefore highlight the need to account for volcanic halogen chemistry when simulating the impact of eruptions such as Sarychev on stratospheric chemistry. The model-simulated evolution of effective radius $\left(r_{\text {eff }}\right)$ reflects new particle formation followed by particle growth that enhances $r_{\text {eff }}$ to reach up to $0.2 \mu \mathrm{m}$ on zonal average. Comparisons of the model-simulated particle number and size distributions to balloon-borne in situ stratospheric observations over Kiruna, Sweden, in August and September 2009, and over Laramie, USA, in June and November 2009 show good agreement and quantitatively confirm the post-eruption particle enhancement. We show that the model-simulated SAOD is consistent with that derived from the Optical Spectrograph and InfraRed Imager 
System (OSIRIS) when both the saturation bias of OSIRIS and the fact that extinction profiles may terminate well above the tropopause are taken into account. Previous modelling studies (involving assumptions on particle size) that reported agreement with (biased) post-eruption estimates of SAOD derived from OSIRIS likely underestimated the climate impact of the 2009 Sarychev Peak eruption.

\section{Introduction}

Explosive volcanic eruptions inject large quantities of sulfur dioxide $\left(\mathrm{SO}_{2}\right)$ into the atmosphere and have the potential to affect global climate (McCormick et al., 1995; Robock, 2000). Volcanic eruptions impact the global radiative budget via the formation of sulfuric acid aerosol particles from the volcanic $\mathrm{SO}_{2}$ emitted. The presence of this particle load at stratospheric altitudes enhances the stratospheric aerosol optical depth (SAOD) and increases the solar backscatter, thereby inducing a cooling at the Earth's surface. The lifetime of sulfuric acid aerosol particles in the stratosphere can reach several years, significantly longer than in the troposphere (days to weeks). Large-magnitude eruptions that inject $\mathrm{SO}_{2}$ directly into the stratosphere therefore typically have more prolonged and widespread (global or hemispheric) impacts than small-magnitude eruptions that typically inject $\mathrm{SO}_{2}$ into the troposphere only. The June 1991 eruption of Mount Pinatubo was a large-magnitude eruption, with a volcanic explosivity index (VEI, as defined in Newhall and Self, 1982) of 6, that had a significant impact on the stratospheric aerosol layer and hence climate (Bluth et al., 1992; Sato et al., 1993; Ammann et al., 2003): global aerosol optical depth (AOD) (in the visible) was enhanced, reaching up to 0.15 , causing a surface cooling of up to $0.5^{\circ} \mathrm{C}$ (Douglass and Knox, 2005; Wunderlich and Mitchell, 2017). In addition, stratospheric halogens (bromine and chlorine, which are present at elevated post-industrial concentrations in the stratosphere as a consequence of past anthropogenic chlorofluorocarbon (CFC) emissions) became activated through reactions on the volcanic aerosol, causing substantial depletion of stratospheric ozone and larger polar ozone holes (Portmann et al., 1996; Solomon et al., 1996; Tilmes et al., 2008).

Moderate-magnitude explosive volcanic eruptions may also reach the stratosphere. However, they typically have a much reduced effect on climate and atmospheric chemistry compared to large-magnitude eruptions (Oman et al., 2005; Kravitz et al., 2010). In general, a smaller mass of $\mathrm{SO}_{2}$ is injected and oxidized to sulfate aerosol. Also, by injecting to lower altitudes, the emissions from moderatemagnitude eruptions are more susceptible to removal by stratospheric-tropospheric exchange processes (Haywood et al., 2010). Nevertheless, as volcanic eruption frequency follows an inverse power law with magnitude (e.g. Sparks,
2003, and references therein), the cumulative impacts of frequent moderate-magnitude eruptions on stratospheric aerosol can be significant (Vernier et al., 2011) and, for example, were identified as a factor in recent decadal climate trends (Solomon et al., 2011; Ridley et al., 2014).

Here, we study the moderate-magnitude eruption of Sarychev Peak volcano, which erupted in mid-June 2009 in the Kuril Islands, Russia $\left(48^{\circ} \mathrm{N}, 153^{\circ} \mathrm{E}, 1512 \mathrm{ma.s.l}\right.$ ), injecting $\mathrm{SO}_{2}$, ash, and also $\mathrm{HCl}$ to the stratosphere. The eruption was classified with a VEI of 4 (the volcanic eruptive index as defined in Newhall and Self (1982) is a logarithmic scale based on the volume of tephra ejected), and the main volcanic emission was injected into heights around 9-14 km as estimated from Infrared Atmospheric Sounding Interferometer (IASI) retrievals (Carn et al., 2016; Carboni et al., 2016). Remote sensing observations over Eureka, Canadian Arctic, showed volcanic aerosol layers from the tropopause up to $16-17 \mathrm{~km} 1$ month after the eruption, that subsequently settled into a more homogeneous layer in the lower stratosphere (O'Neill et al., 2012).

Previous modelling studies of the Sarychev 2009 eruption focused on the injection of $\mathrm{SO}_{2}$, formation of volcanic aerosol, and its radiative and atmospheric chemistry impacts (Haywood et al., 2010; Kravitz et al., 2011; Berthet et al., 2017). However, the models did not explicitly simulate the aerosol microphysical evolution of the volcanic cloud; rather, they used bulk aerosol schemes and/or assumed size distributions. Model-simulated atmospheric impacts of the eruption on, for instance, aerosol optical depth, are highly dependent on the prescribed aerosol size (or effective radius, $r_{\text {eff }}$ ). An $r_{\text {eff }}$ of $0.13 \mu \mathrm{m}$ was assumed in the HadGEM2 model study by Haywood et al. (2010), whilst Kravitz et al. (2011) used scaling to adjust their ModelE (Schmidt et al., 2006) simulations to represent a similar $r_{\text {eff }}$. Measurements that locally quantified the post-eruption volcanic aerosol include groundbased remote sensing (Haywood et al., 2010; Mattis et al., 2010; Kravitz et al., 2011; O'Neill et al., 2012) and balloonborne observations. For example, Kravitz et al. (2010) and Jégou et al. (2013) present in situ balloon-borne observations of size-resolved stratospheric aerosol over Laramie, Wyoming, USA (June and November 2009), and Kiruna, Sweden (August-September 2009), respectively. The estimates of $r_{\text {eff }}$ from all these measurements range from 0.1 to $0.3 \mu \mathrm{m}$, i.e. larger than assumed in the models. Further evidence for a larger particle size comes from an effective radius estimate of $0.1-0.3 \mu \mathrm{m}$ derived from satellite-based observations 1 month after the eruption (Doeringer et al., 2012) and a particle "sedimentation radius" of $0.5-1 \mu \mathrm{m}$ from a model sensitivity study (Günther et al., 2017).

O'Neill et al. (2012) highlight that this discrepancy can translate into large uncertainties in the modelled impacts; e.g. doubling of particle size from that assumed by Haywood et al. (2010) would lead to a 5-fold increase in the hemispherical (per particle) backscattering cross section of sulfate particles. 
Volcanic aerosol from the Sarychev eruption also affected stratospheric halogen chemistry via heterogeneous reactions on the aerosol surface area. The impacts were more modest than found for large-magnitude eruptions such as the 1991 Mt. Pinatubo eruption, but simulations suggest ozone depletion up to $4 \%$ in the lower stratosphere at high latitudes, with local $\mathrm{NO}_{2}$ depletion up to $40 \%$ (Berthet et al., 2017), consistent with balloon-based and satellite observations (Adams et al., 2017).

To evaluate and tune the models, studies to date have relied upon satellite data from the Optical Spectrograph and Infrared Imaging System (OSIRIS) instrument to provide a global estimation of aerosol optical depth. However, comparison between OSIRIS and the models found $\mathrm{a} \approx 1$-month discrepancy in the timing of the SAOD maximum following the eruption. This was attributed to be likely due to deficiencies in the model aerosol microphysics, specifically the absence of nucleation processes (Haywood et al., 2010; Jégou et al., 2013). In subsequent work, Fromm et al. (2014) identified that stratospheric AOD derived from OSIRIS under high aerosol loadings was likely underestimated following volcanic eruptions, due to a saturation effect and because the extinction profiles may terminate well above the tropopause (and therefore miss volcanic aerosol in the lowermost stratosphere). More generally, underestimation of SAOD due to neglect of lower stratospheric volcanic aerosols has also been highlighted by Kravitz et al. (2011); Ridley et al. (2014); Andersson et al. (2015); Mills et al. (2016). As model studies to date have used OSIRIS-derived AODs to evaluate and justify choice of model aerosol parameters such as $r_{\text {eff }}$ (Haywood et al., 2010; Kravitz et al., 2011), this finding invokes the need to reexamine the assumed volcanic aerosol properties in the models. Finally, there have also been recent advances in satellite observations of volcanic gases in the stratosphere. First, new retrievals now enable an improved estimation of $\mathrm{SO}_{2}$ mass injected combined with estimates of plume height from IASI on the MetOp-A satellite (Clarisse et al., 2012; Carboni et al., 2016). Second, recent analysis of satellite data from the Microwave Limb Sounder (MLS) aboard the Aura satellite identifies that the Sarychev volcano co-injected $\mathrm{HCl}$ alongside $\mathrm{SO}_{2}$ into the stratosphere (Carn et al., 2016). The co-injection of volcanic halogens alongside $\mathrm{SO}_{2}$ could modify the resulting atmospheric chemistry/aerosol processing and impacts. In light of these advances, it is instructive to perform a new model-observation study of the Sarychev 2009 eruption and its stratospheric impacts that furthermore benefits from recently developed model capabilities to simulate aerosol microphysics and size evolution.

Here, we present model simulations of stratospheric aerosol evolution and chemistry following the moderatemagnitude 2009 Sarychev eruption using the global Community Earth System Model version 1.0 (CESM1) (Marsh et al., 2013), with its Whole Atmosphere Community Climate Model (WACCM) module for the simulation of the atmosphere, along with the sectional Community Aerosol and
Radiation Model for Atmospheres module (CARMA; Toon et al., 1988) to simulate aerosol microphysics. The sectional scheme distributes particles according to their size over 30 size bins, enabling the evolution of the particle size distribution to be traced in detail with no a priori assumptions on particle size. This model with sectional aerosol was previously used by English et al. (2013) to evaluate aerosol evolution and multi-year impacts from the large-magnitude eruptions of the 1991 Pinatubo eruption and the 100 times stronger Toba eruption (74 000 years before present). Aerosol impacts from large-magnitude eruptions are substantial but limited by particle growth and sedimentation (with a 20-fold increase in AOD following Toba compared to Pinatubo despite its 100fold increase in $\mathrm{SO}_{2}$ injection). The globally averaged effective radius reached 0.45 and $1.9 \mu \mathrm{m}$ after the Pinatubo and Toba eruptions, respectively. English et al. (2013) highlight the need to simulate microphysical processes and advantages of a sectional aerosol representation for a more comprehensive understanding of aerosol evolution following volcanic eruptions. This motivates our study, which applies a sectional aerosol microphysics modelling approach to simulate aerosol evolution following a moderate-magnitude eruption.

The aims of our study are (i) to simulate the stratospheric aerosol evolution following the 2009 Sarychev eruption using a model that explicitly accounts for aerosol microphysical processes using a sectional aerosol scheme, in order to deliver the first model simulations of the size-resolved stratospheric aerosol evolution to assess impacts following the Sarychev eruption; (ii) compare the model output to balloonbased in situ measurements of size-resolved aerosol and to satellite observations of aerosol optical depth, accounting for reported measurement limitations, in order to deliver an improved model assessment of the aerosol impact in the 12 months following the Sarychev eruption; and (iii) to investigate to what extent co-injection of $\mathrm{HCl}$ alongside $\mathrm{SO}_{2}$ may have influenced the subsequent stratospheric aerosol processing and atmospheric chemistry impacts.

\section{Methods}

\subsection{The CESM1(WACCM)-CARMA model: initialization, set-up, and data post-processing}

Model simulations were performed using the global CESM1 using its WACCM module linked to the CARMA module, involving the sulfur cycle with a sectional aerosol scheme (English et al., 2011). Land, sea ice, and rivers were active modules, whereas oceans were data prescribed. The spatial resolution was a longitude/latitude grid of 144 points by 96 , respectively (i.e. approximately $2^{\circ}$ resolution), and over 88 levels of altitude ranging from the ground to approximately $150 \mathrm{~km}$ altitude with approximately 20 levels in the troposphere. Specified dynamics were used, with a nudging towards the Modern-Era Retrospective analysis for Research 
and Applications (MERRA) meteorological data (Rienecker et al., 2011) at every time step (30 min) with a weight factor of 0.1 towards the analysis, for temperature and wind fields. The following surface emissions were prescribed in the model. For $\mathrm{SO}_{2}, \mathrm{NH}_{3}$, black carbon, organic carbon, $\mathrm{NO}_{x}, \mathrm{CH}_{4}$, and $\mathrm{CO}$ emissions, the MACCity data set was used (van der Werf et al., 2006; Lamarque et al., 2010; Granier et al. 2011; Diehl et al., 2012). Anthropogenic $\mathrm{CH}_{4}$ emissions were added from the EDGAR v4.2 database (available at http://edgar.jrc.ec.europa.eu); biogenic $\mathrm{CO}$ emissions were added from the Model of Emissions of Gases and Aerosols from Nature - Monitoring Atmospheric Composition and Climate (MEGAN-MACC) database (Sindelarova et al., 2014). Carbonyl sulfide (OCS) was prescribed using data from Kettle et al. (2002). $\mathrm{CH}_{2} \mathrm{O}$ was prescribed according to the IPCC RCP8.5 scenario (Riahi et al., 2011), and for $\mathrm{H}_{2}$ the ECCAD-GFED3 database was used (van der Werf et al., 2010). For $\mathrm{CO}_{2}, \mathrm{~N}_{2} \mathrm{O}, \mathrm{CCl}_{4}, \mathrm{CF}_{2} \mathrm{ClBr}, \mathrm{CF}_{3} \mathrm{Br}, \mathrm{CH}_{3} \mathrm{Br}$, $\mathrm{CH}_{3} \mathrm{CCl}_{3}, \mathrm{CH}_{3} \mathrm{Cl}$, CFC11, CFC113, CFC12, and HCFC22 emissions, lower boundary conditions were prescribed following CCMI/RCP8.5 data.

Simulations were started on 1 January 2009, using the CESM1(WACCM) initial atmosphere state file at that date. This enabled a 6-month model spin-up period before the eruption injection on 15 June 2009, after which the simulations were continued for 1 year, ending on 31 May 2010. The Sarychev Peak eruption was simulated by injecting volcanic $\mathrm{SO}_{2}$ (and $\mathrm{HCl}$ ) gases into model grid boxes corresponding to the location of the volcano $\left(48^{\circ} \mathrm{N}, 153^{\circ} \mathrm{E}\right)$, over the duration of 15 June 2009, spread evenly between 11 and $15 \mathrm{~km}$ altitude a.s.1.. The model's $2.5^{\circ}$ longitude $\times 1.875^{\circ}$ latitude grid resolution means that the volcanic plume is initially too dilute in the model compared to reality. This is nevertheless a common methodology; see, e.g. Haywood et al. (2010). The vertical distribution of our $\mathrm{SO}_{2}$ injection follows previous model studies. It is a somewhat coarse approximation given that O'Neill et al. (2012) report lidar observations of fine-scale aerosol layers shortly after the eruption. Nevertheless, these were subsequently observed to collapse into a single layer in the lower stratosphere. For the magnitude of the $\mathrm{SO}_{2}$ injection, we use a revised estimate in contrast to previous studies, as discussed below.

A detailed chronology of the Sarychev Peak 2009 eruption can be found in Levin et al. (2010), which identified three explosive periods: on 12-13 June, repeated explosions occurred, reaching heights ranging from 5 to $10 \mathrm{~km}$; an isolated, high-altitude explosion occurred on 14 June, reaching $21 \mathrm{~km}$ altitude; finally, on 15 June, a series of consecutive explosions reached altitudes ranging between 10 and $15 \mathrm{~km}$ (all times are in UTC). The first eruptive clouds on the 1114 June period were mainly ash (Rybin et al., 2011). We neglected the minor, low-altitude (inferior to $5 \mathrm{~km}$ ) explosions reported on 11 and 16 June, and injected $\mathrm{SO}_{2}$ continuously for a $24 \mathrm{~h}$ period on 15 June spread evenly between 11 and $15 \mathrm{~km}$ altitude a.s.l.. The timing of the $\mathrm{SO}_{2}$ emissions is based on $\mathrm{SO}_{2}$ satellite retrievals from IASI (Clarisse et al., 2012; Carn et al., 2016; Carboni et al., 2016), MODIS (MODerate-resolution Imaging Spectroradiometer; Rybin et al., 2011; Realmuto and Berk, 2016), and OMI (Ozone Monitoring Instrument; Theys et al., 2015), which all show that the majority of high altitude $\mathrm{SO}_{2}$ was released on 15 June (and possibly in the early morning of 16 June). Haywood et al. (2010) used a total injection mass of $1.2 \mathrm{Tg} \mathrm{SO}_{2}$, which was the $\mathrm{SO}_{2}$ total mass value retrieved on 16 June with IASI. An update of the $\mathrm{SO}_{2}$ algorithm (Clarisse et al., 2012) found a maximum $\mathrm{SO}_{2}$ mass value of around $0.9 \mathrm{Tg}$, a value which was confirmed with subsequent updates of that algorithm (Carn et al., 2016). It is also consistent with retrievals from OMI (Theys et al., 2015) and MODIS (Realmuto and Berk, 2016). In contrast, the IASI retrievals reported in Carboni et al. (2016) found that the transient $\mathrm{SO}_{2}$ burden reached only up to $0.6 \mathrm{TgSO}_{2}$. We consider though that $0.9 \mathrm{Tg}$ of $\mathrm{SO}_{2}$ is the best estimate for the mass of $\mathrm{SO}_{2}$ injected by the Sarychev eruption into the UTLS. We did not consider any ash emissions.

In a second simulation, $27 \mathrm{Gg} \mathrm{HCl}$ was co-injected alongside the $0.9 \mathrm{Tg}$ of $\mathrm{SO}_{2}$. This initialization follows the recent identification of a localized stratospheric $\mathrm{HCl}$ enhancement following the Sarychev eruption (Carn et al., 2016), based on analysis of Microwave Limb Sounder (MLS) satellite observations, reporting a $\mathrm{HCl} / \mathrm{SO}_{2}$ mass ratio of around $3 \%$. Since the low vertical resolution of MLS in the lower stratosphere makes it difficult to infer the precise injection altitude of $\mathrm{HCl}$, we assumed an $\mathrm{HCl}$ injection altitude identical to that of $\mathrm{SO}_{2}$. A control run without the volcanic gas injection was also performed, enabling anomalies to be calculated. In the present paper, we will refer to control runs as "volcano-off" simulations and to runs including the eruption as "volcanoon" simulations.

The CESM1(WACCM) atmospheric chemistry scheme includes a detailed sulfur cycle and key stratospheric nitrogen $\left(\mathrm{NO}_{y}\right)$, and halogenated (i.e. chlorine and bromine) and hydrogenated (in particular $\mathrm{HO}_{x}$ radicals) compounds. The formation and microphysics of sulfuric acid aerosol particles simulated by the CARMA module are described in detail in English et al. (2011).

The CARMA module in sectional configuration yields particle concentration across 30 size bins ranging from approximately $0.68 \mathrm{~nm}$ to $3.25 \mu \mathrm{m}$ in dry diameter. Effective radius is also provided as a direct model output. Postprocessing of the model output was used to determine wet particle size distributions, extinctions, and optical depth. In each model grid cell, the wet diameter of each size bin was calculated using a (hygroscopic growth) parameterization of $\mathrm{H}_{2} \mathrm{SO}_{4(\mathrm{aq})}$ particle volume as a function of acid weight percentage $\left(\mathrm{wt} \% \mathrm{H}_{2} \mathrm{SO}_{4}\right)$, ambient humidity, and temperature following Tabazadeh et al. (1997). Extinctions at 750 and $550 \mathrm{~nm}$ were calculated by combining the particle concentrations across the sectional size bins with the corresponding wet radii and particle refractive indices following Beyer et al. 
(1996), using a Mie scattering code at the desired wavelength (van de Hulst and Twersky, 1957). The aerosol extinctions were integrated with altitude over the stratosphere to yield SAOD.

\subsection{Balloon-borne in situ and satellite-based remote sensing observations of aerosol and $\mathrm{SO}_{2}$}

The model $\mathrm{SO}_{2}$ output (from simulations with and without $\mathrm{HCl}$ co-injection) is compared to vertical columns of $\mathrm{SO}_{2}$ and total (northern hemispheric) $\mathrm{SO}_{2}$ burden derived from IASI. The Infrared Atmospheric Sounding Interferometer is an instrument that has been present aboard the MetOpA satellite since the end of 2006. It is a spectrometer measuring infrared light spectra at nadir. Its primary goal is to assess temperature and water vapour content of the atmosphere, but it can also be used to retrieve the atmospheric concentrations of various gases, including $\mathrm{SO}_{2}$ (Clarisse et al., 2008; Carboni et al., 2016). IASI provides global coverage twice a day, and its footprint ranges from circular $(12 \mathrm{~km}$ diameter at nadir) to elliptical (up to $20 \mathrm{~km}$ by $39 \mathrm{~km}$ at the end of the swath). For this comparison, we use the IASI retrieval of $\mathrm{SO}_{2}$ by Clarisse et al. (2012). The IASI data set and retrieval algorithm used for this precise eruption can be considered as showing a lower threshold of around $0.3 \mathrm{DU}$, and $\mathrm{SO}_{2}$ loads can be expected to have a 10-20\% uncertainty. IASI altitude retrievals have a typical sensitivity of $1-2 \mathrm{~km}$. We also compare our results to HadGEM2 model simulations of $\mathrm{SO}_{2}$ and earlier IASI $\mathrm{SO}_{2}$ retrievals reported by Haywood et al. (2010).

Comparisons of the modelled aerosols with in situ measurements are two-fold. First, we compare the model's output with size-resolved aerosol measurements carried out with the balloon-borne Stratospheric and Tropospheric Aerosol Counter (STAC) optical particle counter (OPC) instrument over Kiruna, Sweden, on 2, 7, and 18 August 2009, and 18 May 2010. STAC can be borne under stratospheric balloon gondolas and can measure low concentrations in aerosols down to approximately $10^{-4} \mathrm{~cm}^{-3} \mu \mathrm{m}^{-1}$ (Ovarlez and Ovarlez, 1995; Renard et al., 2005, 2010). Particles are classified by their diameters into tuneable size bins ranging from a few tenths of micrometre to a few micrometres. The counts in each size bin are normalized by the bin width to yield a size distribution. The uncertainty, defined as the relative standard deviation (SD), is $60 \%$ for aerosol concentrations of $10^{-3} \mathrm{~cm}^{-3}, 20 \%$ for $10^{-2} \mathrm{~cm}^{-3}$, and $6 \%$ for concentrations higher than $10^{-1} \mathrm{~cm}^{-3}$. STAC was operated successfully on eight different balloon flights throughout the August-September 2009 period over Kiruna, Sweden $\left(68^{\circ} \mathrm{N}, 20^{\circ} \mathrm{E}\right)$, as part of the StraPolÉté campaign (French acronym for Stratosphère Polaire en Été), and also in May 2010, as part of the AEROWAVE project (acronym for AEROsols, WAter Vapour and Electricity). Measurements of the STAC instruments are available online at https: //cds-espri.ipsl.upmc.fr. During these flights, it was demon- strated that STAC passed through the Sarychev plume (Jégou et al., 2013), as explored further in the present paper. Our comparison focuses on the submicron range between $\approx 0.3$ and $1 \mu \mathrm{m}$ diameters. We have performed an interpolation of the counts from the model's size bins to the STAC size bins (and from the model pressure levels to the observed pressure of the balloon payload) in order to enable a direct comparison.

Second, we also compare the model's aerosol output with in situ measurements carried out by the OPC of the University of Wyoming (Deshler et al., 2003), flown on stratospheric balloons launched from Laramie, USA $\left(41^{\circ} \mathrm{N}, 105^{\circ} \mathrm{W}\right)$, on 22 June 2009 and 7 November 2009 (Kravitz et al., 2011). For comparison to the model, total particle number above two diameter threshold sizes is considered here: $d>20 \mathrm{~nm}$ (condensation nuclei, $\mathrm{CN}$ ) and $d>0.5 \mu \mathrm{m}$ (nuclei, $\mathrm{N}$ ). Uncertainties are 85,25 , and $8 \%$ for concentrations of $10^{-3}, 10^{-2}$, and $10^{-1} \mathrm{~cm}^{-3}$, respectively (Deshler et al., 2003). These data are available from ftp://cat.uwyo.edu/pub/permanent/balloon/ Aerosol_InSitu_Meas/US_Laramie_41N_105W/. They have been derived by the University of Wyoming as follows: the measurement of $\mathrm{N}$ is calculated directly from the OPC instrument. The $\mathrm{CN}$ is derived from a condensation nuclei counter co-deployed on the balloon payload. Note that both STAC and University of Wyoming OPCs have been compared by Renard et al. (2002).

Model SAOD was compared to that derived from extinction measurements by the OSIRIS aerosol instrument (aboard the Odin satellite). OSIRIS is a limb sounder that is able to provide information on the vertical distribution of atmospheric aerosols (Bourassa et al., 2007, 2008) from the upper troposphere up to the lower mesosphere through the analysis of scattered sunlight. This Canadian instrument has been active since November 2001 aboard the Swedish satellite Odin (Llewellyn et al., 2004). Its global coverage reaches up to $82^{\circ}$ in latitude. Odin evolves on a Sun-synchronous orbit, and therefore the availability of OSIRIS's measurements is latitude and time dependent. Our analysis focuses on extinction measurements from OSIRIS version 5.07, available from http://odin-osiris.usask.ca/. Importantly, a novel aspect of our study is that our analysis specifically accounts for instrument errors or limitations as reported by Fromm et al. (2014). Model output data have been degraded accordingly. First, the modelled extinctions have been made to saturate at an upper threshold of $2.5 \times 10^{-3} \mathrm{~km}^{-1}$; then, extinctions have been only integrated above a certain altitude, dependent on the latitude: a linear variation of this lower limit was assumed from $0.5 \mathrm{~km}$ above the tropopause at the Equator up to $5.5 \mathrm{~km}$ above the tropopause at the poles. Further details are given in Sect. 3.4. 


\section{Results}

\subsection{Spatial and temporal evolution of volcanic $\mathrm{SO}_{2}$ vertical column densities}

Figure 1 shows vertical column densities of $\mathrm{SO}_{2}$ from the CESM1(WACCM) simulation in which both volcanic $\mathrm{SO}_{2}$ and $\mathrm{HCl}$ were injected (Fig. 1b) and a comparison with IASI retrievals (Fig. 1a). Both sets of maps are shown with the same lower threshold in terms of Dobson units, corresponding to an estimated lower threshold of 0.3 DU in IASI's retrievals for this precise eruption and for the IASI retrieval algorithm used (Clarisse et al., 2012). The spatial and temporal evolution of the Sarychev $\mathrm{SO}_{2}$ plume is reasonably well simulated by the CESM1(WACCM) runs throughout the first fortnight following the eruption. There are some notable discrepancies, for instance, on 16 June 2009 south-west of Alaska: this is likely due to our simulation not accounting for the small amount of $\mathrm{SO}_{2}$ that was emitted before the main eruption on 15 June 2009. Also, Asian pollution (close to $0.3 \mathrm{DU}$ ) is evident in the simulations shown in Fig. 1 but not observed by IASI, likely due to the reduced sensitivity of the IASI retrievals to $\mathrm{SO}_{2}$ below $5 \mathrm{~km}$ altitude. To quantify the spatial-amplitude match between the two sets of data, we chose a colocation index calculated as

$\rho=\frac{\mathbb{E}\left[\left(P_{1}-\mu_{1}\right)\left(P_{2}-\mu_{2}\right)\right]}{\sigma_{1} \sigma_{2}}$,

where $P_{1}$ and $P_{2}$ are the two-dimensional matrices representing the spatial $\mathrm{SO}_{2}$ loads (for model and satellite retrievals), sampled over the same spatial grid, and stacked into one-dimensional vectors; $\mu_{\{1 ; 2\}}$ and $\sigma_{\{1 ; 2\}}$ are their respective means and SDs. It is expected that the index drops quite quickly after the eruption due to greater dispersion in the model on the $2 \times 2$ degree grids than in the finer-scale (tens of kilometres) IASI observations. Colocation indices were calculated over the first fortnight following the eruption (Table 1) for the simulation with $\mathrm{SO}_{2}$ injection only and with $\mathrm{HCl}$ co-injection alongside $\mathrm{SO}_{2}$. As can be noted from Table 1, colocation indices show comparable values for both model runs. This indicates broadly similar $\mathrm{SO}_{2}$ dispersion in the model runs.

The spatial and temporal evolution of the plume in our study is consistent with the results of Wu et al. (2017), where AIRS data are presented along with results of simulations by a particle dispersion model.

\subsection{Lifetime, burden of volcanic $\mathrm{SO}_{2}$, and role of co-injected $\mathrm{HCl}$}

Figure 2 shows the modelled northern hemispheric $\mathrm{SO}_{2}$ burden in teragrams, calculated by integrating the model anomalies from CESM1(WACCM) simulations with $\mathrm{SO}_{2}$ injection only and with $\mathrm{SO}_{2}$ and $\mathrm{HCl}$ co-injection (anomaly denotes a volcano-on simulation from which the volcano-off control run has been subtracted). Two adjusted CESM1(WACCM) model results are also presented that only include data over columns with $>0.3 \mathrm{DUSO}_{2}$ to enable a better comparison to the IASI observations. Alongside is shown the observed evolution in northern hemispheric $\mathrm{SO}_{2}$ burden derived from the IASI retrieval by Clarisse et al. (2012) (which has a lower threshold of around 0.3 DU; see Sect. 2.2). Finally, we also show the northern hemispheric $\mathrm{SO}_{2}$ burden as simulated using the HadGEM2 model (Haywood et al., 2010) and the IASI retrieval reported in that same study, both of which estimated $1.2 \mathrm{Tg} \mathrm{SO} \mathrm{S}_{2}$ injection in contrast to the revised IASI analysis (Clarisse et al., 2012) that yielded $0.9 \mathrm{Tg} \mathrm{SO}_{2}$ used in our study.

A notable result is the slower decline in $\mathrm{SO}_{2}$ burden for the model run with volcanic $\mathrm{SO}_{2}$ and $\mathrm{HCl}$ co-injection than volcanic $\mathrm{SO}_{2}$ (only). There is also a corresponding slower increase in the sulfate aerosol burden (Fig. 3).

The presence of $\mathrm{HCl}$ slows down the oxidation of $\mathrm{SO}_{2}$ to sulfuric acid aerosol particles and hence lengthens the $e$ folding time of $\mathrm{SO}_{2}$ in the stratosphere by about 2 days (see calculations below). This occurs as a result of the competition between their two main oxidation reactions involving $\mathrm{OH}$. These are

$\mathrm{HCl}+\mathrm{OH} \rightarrow \mathrm{Cl}+\mathrm{H}_{2} \mathrm{O}$

and the trimolecular reaction (where $M$ is a third body, e.g. $\mathrm{N}_{2}$ or $\mathrm{O}_{2}$ )

$\mathrm{SO}_{2}+\mathrm{OH}+M \rightarrow \mathrm{HSO}_{3}+M$,

where $\mathrm{HSO}_{3}$ subsequently leads to the formation of $\mathrm{H}_{2} \mathrm{SO}_{4}$ through the reaction sequence described by Weisenstein et al. (1997). This conversion of $\mathrm{SO}_{2}$ to $\mathrm{H}_{2} \mathrm{SO}_{4}$ is limited by the rate of Reaction (R2) below $40 \mathrm{~km}$ in altitude. Competition between Reactions (R2) and (R1) results in a slower rate of oxidation of volcanic $\mathrm{SO}_{2}$ in the presence of co-injected $\mathrm{HCl}$.

A second notable result is that all the unadjusted model outputs overestimate the $\mathrm{SO}_{2}$ burden following the eruption compared to IASI measurements. The HadGEM2 model $\mathrm{SO}_{2}$ exceeds the Haywood et al. (2010) IASI observations for the whole period. The unadjusted CESM1(WACCM) outputs also exceed the Clarisse et al. (2012) IASI observations after a few days. This behaviour contrasts with the two adjusted CESM1(WACCM) model outputs that correct for the $0.3 \mathrm{DU} \mathrm{SO}_{2}$ lower value of the particular IASI retrievals used. The adjusted CESM1(WACCM) model outputs remain in close agreement with the observed post-eruption $\mathrm{SO}_{2}$ burden for the first 1-2 weeks, after which the model-simulated $\mathrm{SO}_{2}$ burdens decline more rapidly than the IASI $2012 \mathrm{ob}-$ servations. This evolution can be expected: a greater dispersion in the $2^{\circ} \times 2^{\circ}$ model grid cells than in reality (and than observed by the IASI footprint of tens of kilometres) would cause an underestimation of the model $\mathrm{SO}_{2}$ burden compared to IASI. This effect will become more pertinent with dilution over time as the $\mathrm{SO}_{2}$ column approaches the $0.3 \mathrm{DU}$ limit. 
(a)

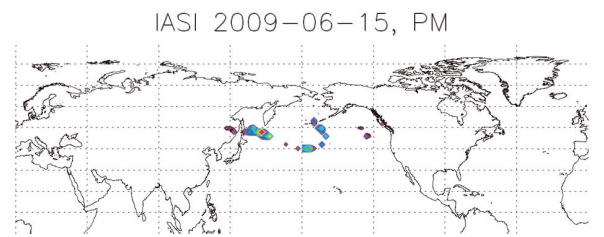

IASI 2009-06-16, PM

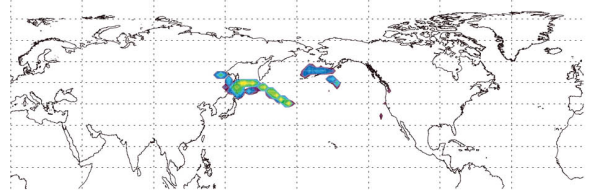

IASI 2009-06-17, PM

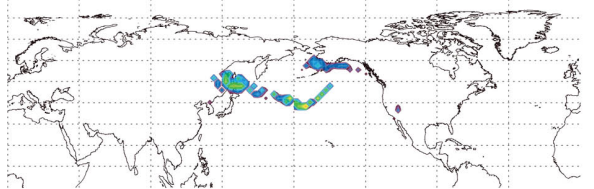

IASI 2009-06-18, PM

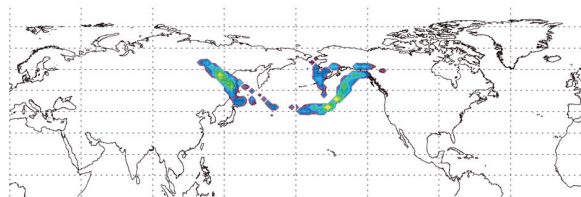

IASI 2009-06-20, PM

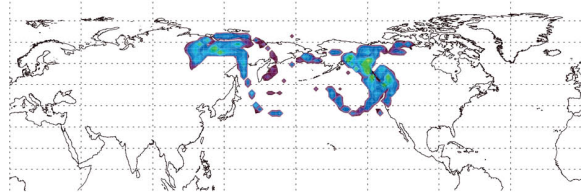

IASI 2009-06-23, PM

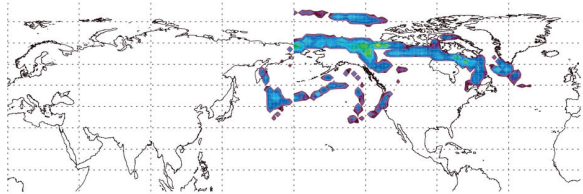

IASI 2009-06-25, PM

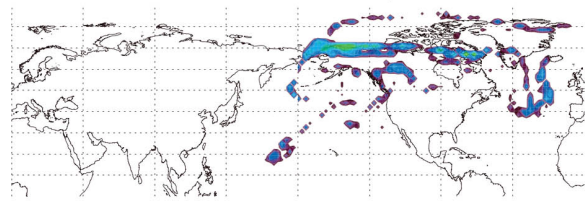

IASI 2009-06-27, PM

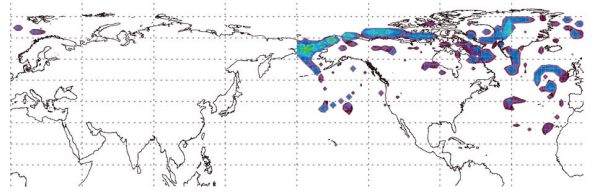

(b)

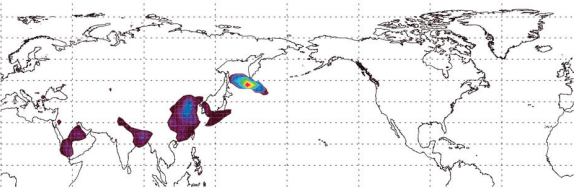

WACCM 2009-06-16, PM

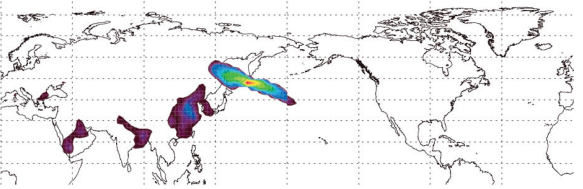

WACCM 2009-06-17, PM

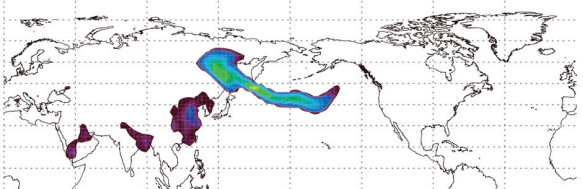

WACCM 2009-06-18, PM

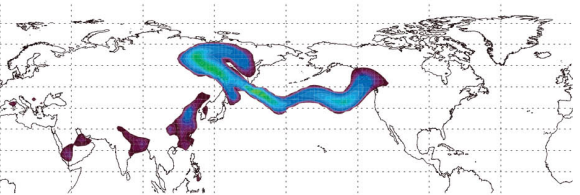

WACCM 2009-06-20, PM

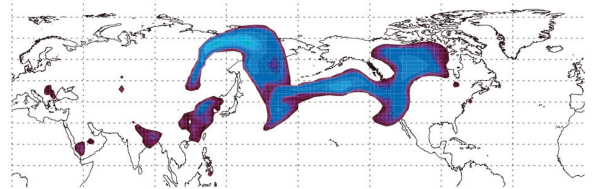

WACCM 2009-06-23, PM

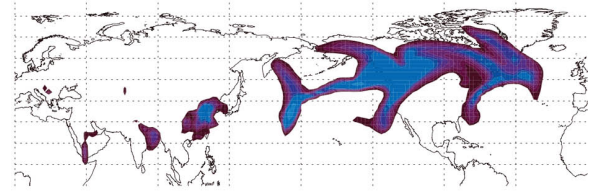

WACCM 2009-06-25, PM

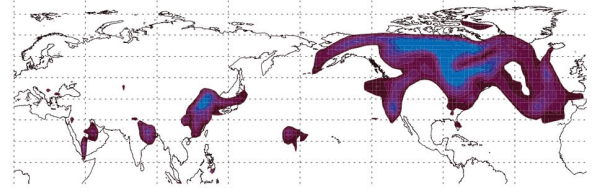

WACCM 2009-06-27, PM

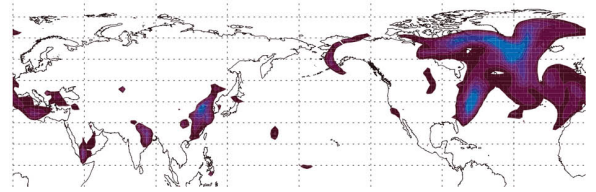

Figure 1. Spatial and temporal evolution of vertical column densities of $\mathrm{SO}_{2}$ (in Dobson units, DU) over 1-2 weeks following the Sarychev eruption according to IASI satellite observations (a) and simulated by the CESM1(WACCM) model (b). A threshold of 0.3 DU was applied, corresponding to the lower threshold for this precise IASI retrieval (Clarisse et al., 2012). The CESM1(WACCM) model data correspond to instantaneous output at midnight, whereas the IASI data are gathered over the whole of the post meridiem period. 
Table 1. Colocation indices quantifying the spatial-amplitude agreement in the volcanic $\mathrm{SO}_{2}$ vertical column densities simulated by CESM1(WACCM) compared to IASI observations over the Northern Hemisphere for 1-2 weeks after the eruption (dates corresponding to Fig. 1); see Eq. (1) for details of the computation.

\begin{tabular}{lrrrrrrrr}
\hline Date & 15 June & 16 June & 17 June & 18 June & 20 June & 23 June & 25 June & 27 June \\
\hline Colocation index, with $\mathrm{HCl}$, in \% & 90.34 & 41.29 & 17.61 & 20.26 & 16.60 & 12.38 & 11.36 & 5.36 \\
Colocation index, without $\mathrm{HCl}$, in \% & 90.36 & 41.25 & 17.55 & 20.23 & 16.62 & 12.85 & 11.30 & 5.48 \\
\hline
\end{tabular}

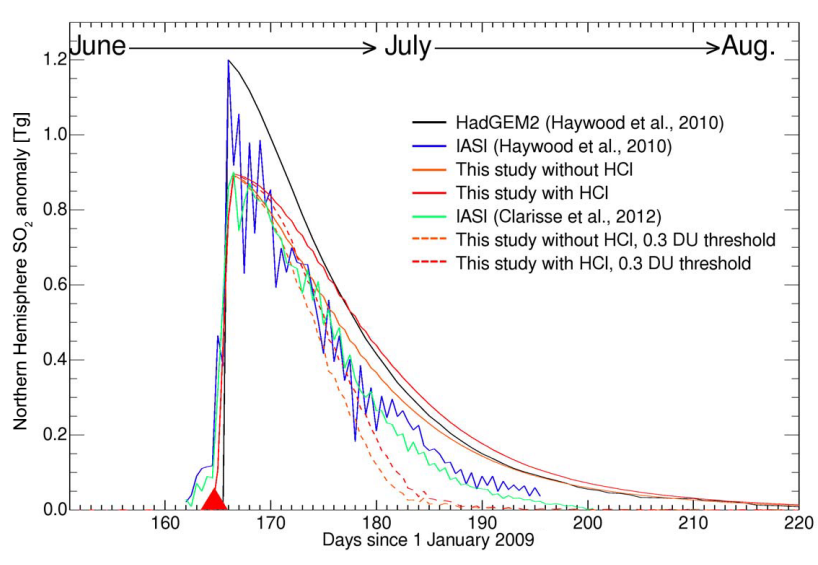

Figure 2. Temporal evolution of the $\mathrm{SO}_{2}$ burden anomaly (in $\mathrm{Tg}$ ), integrated over the Northern Hemisphere over June-August 2009. Model anomalies are shown for simulations that injected $\mathrm{SO}_{2}$ only (orange) and with co-injection of $\mathrm{HCl}$ (red), alongside the IASI retrieval (green) with maximum burden of $0.9 \mathrm{TgSO}$. Also shown are adjusted model outputs that account for the 0.3 DU IASI lower threshold for this particular case (red and orange dashed lines). For comparison, the previously reported model study and IASI retrieval of Haywood et al. (2010) that assumed a higher maximum burden of $1.2 \mathrm{Tg} \mathrm{SO}_{2}$ are also depicted (black and blue lines, respectively).

In summary, we find that the CESM1(WACCM) model run (adjusted output) with $\mathrm{SO}_{2}$ and $\mathrm{HCl}$ co-injection gives the best agreement with the IASI $\mathrm{SO}_{2}$ observations. The simulation with $\mathrm{SO}_{2}$ with $\mathrm{HCl}$ injection therefore forms the basis for further analysis in Sect. 3.6.

Our model-observation comparison of $\mathrm{SO}_{2}$ burden trends can also be quantified in terms of the $e$-folding time. The definition of the $e$-folding time $\tau$ is the following: let $M(t)$ be the concentration of a species through time; if we assume it follows an exponential decay over a certain period of time $t>t_{0}$, then $\tau$ is such as $\forall t>t_{0}, M(t+\tau)=M(t) / e$; i.e. $\tau$ corresponds to the time by which the concentration falls to $1 / e$ of its initial value. For these calculations, we choose the $\mathrm{SO}_{2}$ burden maximum as the initial value $(0.9 \mathrm{Tg}$ in our study). The $e$-folding time constant for $\mathrm{SO}_{2}$ is approximately 17.0 days for the simulation including $\mathrm{HCl}$, about 2 days longer than the approximately 15.0 days for the simulation that was run without $\mathrm{HCl}$. When these CESM1(WACCM) model outputs are adjusted to correct for the $0.3 \mathrm{DUSO}_{2}$ lower value of the particular IASI retrievals used, they yield

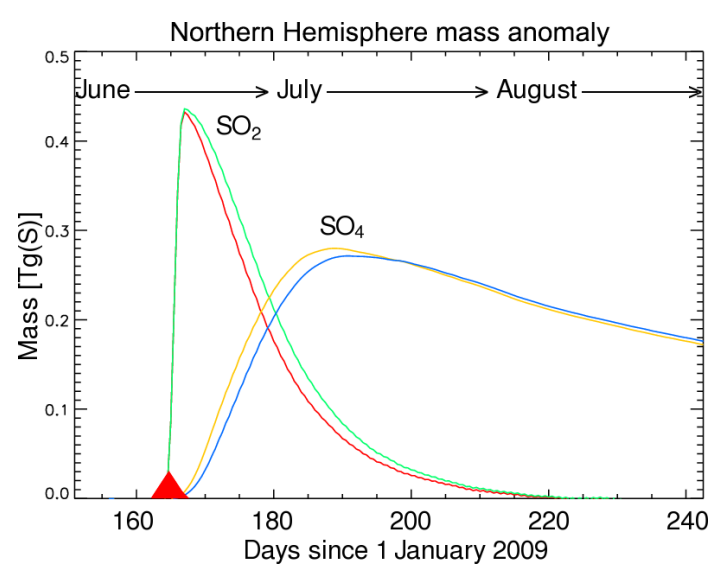

Figure 3. Temporal evolution of total $\mathrm{SO}_{2}$ and $\mathrm{SO}_{4}$ burdens (Tg sulfur), integrated over the Northern Hemisphere over JuneAugust 2009 (the eruption is depicted by the red triangle). Model anomalies are shown for runs with injection of $\mathrm{SO}_{2}$ only (red and yellow for $\mathrm{SO}_{2}$ and $\mathrm{SO}_{4}$, respectively) and with co-injection of $\mathrm{HCl}$ (green and blue for $\mathrm{SO}_{2}$ and $\mathrm{SO}_{4}$, respectively).

$e$-folding time constants of 11.5 and 10.0 days, respectively. For the IASI SO 2 retrieval of Clarisse et al. (2012), we calculate 12.0 days, i.e. very similar to the adjusted model simulation with $\mathrm{SO}_{2}$ and $\mathrm{HCl}$ co-injection (11.5 days). For comparison, Haywood et al. (2010) report that the HadGEM2 model yields a 13- to 14-day $\mathrm{SO}_{2} e$-folding time (assuming a higher $\mathrm{SO}_{2}$ injection of $1.2 \mathrm{Tg}$ and no $\mathrm{HCl}$ co-injection). Regarding IASI observations, Haywood et al. (2010) report an IASI $\mathrm{SO}_{2} e$-folding time of 10-11 days, whilst using our method we calculate 9.0 days for the IASI retrieval of 2010. This is summarized in Table 2.

\subsection{Comparison of the model to in situ balloon-based measurements of size-resolved aerosol}

Here, we compare size-resolved aerosol concentrations from our simulations with in situ measurements from balloonborne OPCs over Laramie, USA (June and November 2009), and Kiruna, Sweden (August and September 2009). It should be emphasized that the instruments are likely to detect a wider range of particles and particle compositions present in the stratosphere, i.e. internally and externally mixed particles with some organic and meteoric components (Murphy et al., 2014), whereas our model simulations provide pure 
Table 2. Comparison of the calculated $\mathrm{SO}_{2} e$-folding times for this study and Haywood et al. (2010). Two sets of IASI data are investigated: 2010 and 2012 retrievals. For the sake of the comparison with the satellite data, a lower threshold of 0.3 DU is applied whenever possible. The most recent IASI data (2012) yield a value close to that calculated with the model simulation of this study with $\mathrm{SO}_{2}$ and $\mathrm{HCl}$ co-injection. N/A indicates data that are not available.

\begin{tabular}{|c|c|c|c|c|c|c|}
\hline & $\begin{array}{l}\text { This study, } \\
\text { model } \\
\text { with } \mathrm{HCl}\end{array}$ & $\begin{array}{l}\text { This study, } \\
\text { model } \\
\text { without } \mathrm{HCl}\end{array}$ & $\begin{array}{l}\text { Haywood et al. (2010) } \\
\text { HadGEM2 model }\end{array}$ & $\begin{array}{l}\text { Haywood et al. (2010) } \\
\text { IASI } 2010\end{array}$ & $\begin{array}{l}\text { This study, } \\
\text { IASI } 2010\end{array}$ & $\begin{array}{l}\text { This study, } \\
\text { IASI } 2012\end{array}$ \\
\hline $\mathrm{SO}_{2} e$-folding time & $\approx 17.0$ days & $\approx 15.0$ days & $\approx 13 \approx 14$ days & N/A & N/A & N/A \\
\hline With 0.3 DU threshold & $\approx 11.5$ days & $\approx 10.0$ days & N/A & $\approx 10 \approx 11$ days & $\approx 9.0$ days & $\approx 12.0$ days \\
\hline
\end{tabular}

sulfuric acid aerosol particles only. Nevertheless, these are expected to be the dominant source of aerosol in the lower stratosphere in the months following the Sarychev Peak 2009 eruption.

First, we compare the model to measurements carried out by the University of Wyoming OPC (Deshler et al., 2003) during balloon-borne flights over Laramie, Wyoming (USA, $41^{\circ} \mathrm{N}, 105^{\circ} \mathrm{W}$ ), on 22 June and 7 November 2009. These observations were made 1 week and nearly 5 months after the Sarychev eruption, respectively. Kravitz et al. (2011) previously suggested that a significant volcanic influence can be seen in the data from 7 November but not on 22 June, based on comparison with balloon flights from other years. Here, we compare the data directly to aerosol simulated by our model runs.

Figure 4 shows both the model and measured aerosol particle number concentrations over Laramie for two particle size ranges: $d>20 \mathrm{~nm}$ (noted $\mathrm{CN}$, for condensation nuclei) and $d>0.5 \mu \mathrm{m}$ (noted $\mathrm{N}$ ). Overall, there is good general agreement between simulated and measured values in terms of number concentrations and in the general trend with respect to altitude and size range separation. Note that modelmeasurement differences are greater in the troposphere since only sulfuric acid particles are simulated.

The upper panel of Fig. 4 (22 June 2009) shows that the volcano-off simulation reproduces the in situ observations of particle number with a very good agreement, supporting the hypothesis of Kravitz et al. (2011) that there was no significant volcanic influence on this day. However, the volcanoon simulation in fact simulates the presence of a volcanic plume, as can be seen by enhancements in $\mathrm{CN}$ and $\mathrm{N}$ between 13 and $15 \mathrm{~km}$ altitude. We note that the precise geographical location of plume structures is difficult to simulate using low-resolution simulations just 1 week after the eruption. Remote sensing observations suggest the initial presence of multiple aerosol layers in the stratosphere that subsequently collapsed into a single layer (O'Neill et al., 2012), whereas our CESM1(WACCM) model study assumes injection over $11-15 \mathrm{~km}$. We also suggest that model horizontal resolution effects are a further possible source of error in the volcano-on simulation that might have led to anomalous sulfate plume structure over the measurement location. A geographic 2-D map of the vicinity of Laramie that shows model-simulated sulfuric acid aerosol particles at $13 \mathrm{~km}$ altitude (Fig. A1) show that the location of the measurements lies on the edge of an aerosol plume structure simulated by the model. Diffusion on the model grids $\left(2^{\circ} \times 2^{\circ}\right.$ resolution $)$ or uncertainties in the initialization altitude could therefore lead to modelled plume structure over Laramie that is not evident in the observations.

Conversely, on 7 November, the volcanic plume is simulated to be much more homogeneous (and dilute), covering a larger area that encompasses Laramie. The lower panel of Fig. 4 shows modelled and observed aerosol particle number concentrations for 7 November 2009. For the $d>0.5 \mu \mathrm{m}$ size range $(\mathrm{N})$, the agreement between the volcano-on simulation and the in situ measurements below $17 \mathrm{~km}$ indicates that volcanic aerosol particles were still present and detectable over Laramie nearly 5 months after the eruption, and their presence can be quantitatively reproduced by the CESM1(WACCM) model. The profiles from both volcanoon and volcano-off simulations are very close in the $d>$ $20 \mathrm{~nm}$ size range $(\mathrm{CN})$ indicating the progressive return of the simulated concentrations to background conditions for this size range.

Next, we compare the CESM1(WACCM) simulations to in situ aerosol measurements made by the STAC instrument on a balloon gondola in northern Sweden. Figure 5 compares the particle counts observed by STAC and the sulfate particle concentrations simulated by the WACCM model for the same location (Kiruna, Sweden, $67^{\circ} \mathrm{N}, 20^{\circ} \mathrm{E}$ ), and times: 2, 7, and 18 August 2009. A comparison is also shown for 18 May 2010 when the stratosphere can be considered to be close to background conditions. The model outputs have been interpolated to the pressure observed by the balloon payload and to the specific size bins of the STAC instrument covering 0.325 to $0.885 \mu \mathrm{m}$ mean diameter.

In Fig. 5, a volcanic sulfate aerosol plume can clearly be identified between 11 and $19 \mathrm{~km}$ altitude for all flights in August 2009. This is demonstrated in the third column of the figure by an important difference in modelled particle number over the size bins of the STAC for the volcano-on and volcano-off simulations: total particle number on the STAC diameter range is enhanced by the volcanic eruption by between 1 and 2 orders of magnitude depending on the altitude. 


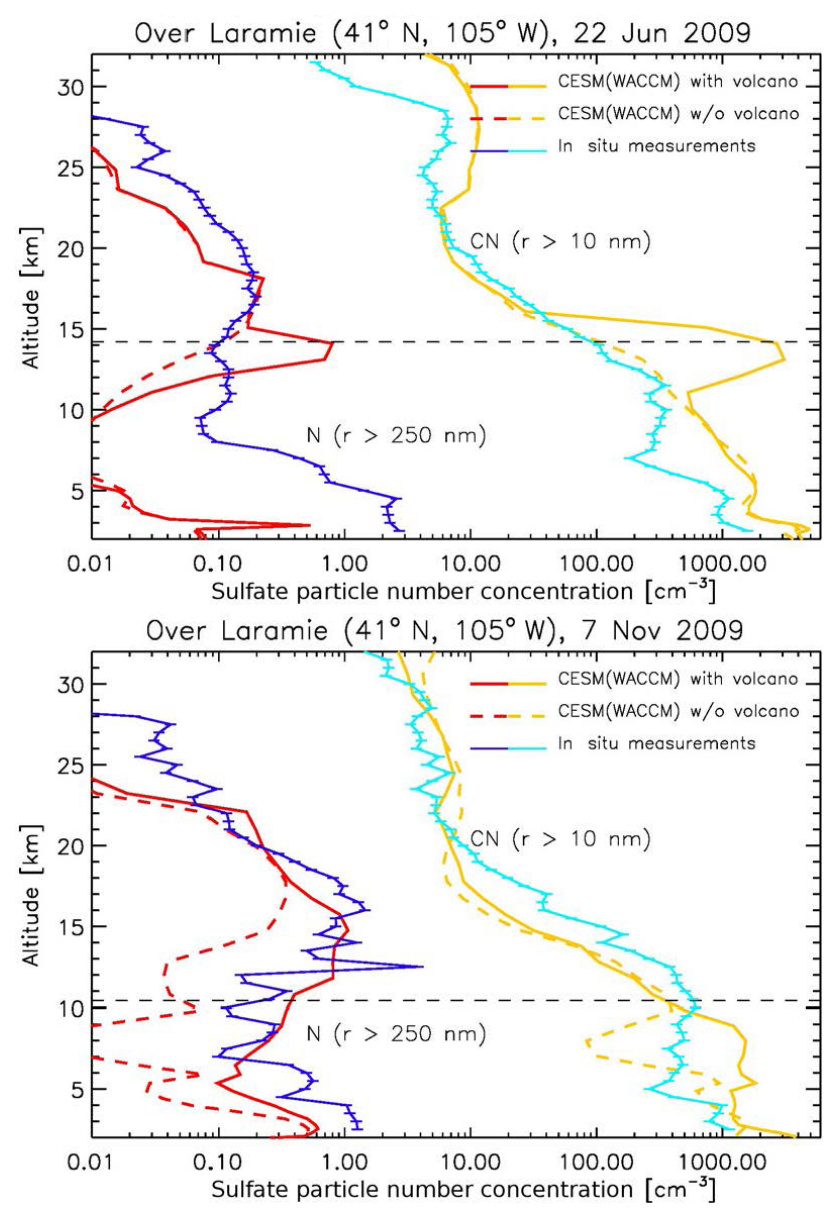

Figure 4. Comparison of particle number concentration over Laramie (USA; $41^{\circ} \mathrm{N}, 105^{\circ} \mathrm{W}$ ), simulated by the CESM1(WACCM) model (red/orange lines: simulations with and without the Sarychev eruption are shown as solid and dashed lines, respectively) and by balloon-borne in situ measurements (blue/cyan lines) for 22 June and 7 November 2009. Two size ranges are shown: $d>20 \mathrm{~nm}(\mathrm{CN})$ and $d>0.5 \mu \mathrm{m}(\mathrm{N})$. The model tropopause height is depicted by the dashed grey line. Model uncertainties are greater in the troposphere. On 22 June 2009, the presence of a volcanic plume over Laramie is simulated in the model (evident in both $\mathrm{CN}$ and $\mathrm{N}$ at the tropopause; discussed in the text) but not evident in the observations. On 7 November 2009, the presence of a more dilute volcanic plume is simulated in the model (evident in $\mathrm{N}$ only) that is consistent with the observed $\mathrm{N}$ in the lower stratosphere.

Total number simulated in the volcano-on simulation is in good general agreement with the STAC observations.

There are some discrepancies between model and observations at higher and lower altitudes: at lower altitudes, the model yields lower counts than the instrument's counts: this is likely due to the presence in the troposphere of nonsulfate aerosols unaccounted for by the model. For the discrepancies above the plume's altitude, the radiometer MicroRADIBAL (French acronym for Micro RADIomètre BAL- lon) (Brogniez et al., 2003; Renard et al., 2008), flown alongside STAC, identified the presence of some light-absorbing particles around $20 \mathrm{~km}$ altitude (Jégou et al., 2013): these might have affected the STAC measurements (STAC is designed for sulfate particle detection) and were also not included in the model. Their origin is still to be determined. Nevertheless, the good agreement in total number between model and observations in the lower stratosphere (corresponding to the main influence of the volcanic plume) confirms the strong impact of the Sarychev eruption on aerosol number.

Comparing these aerosol observations above Kiruna in August to those above Laramie in November on an order of magnitude basis, the Laramie measurements have $\approx 1 \mathrm{~cm}^{-3}$ particles of diameter greater than $0.5 \mu \mathrm{m}$ at $14 \mathrm{~km}$ altitude in November, whereas measurements over Sweden in August of the same year show approximately 10 to 100 times more particles of size greater than $0.4 \mu \mathrm{m}$ in diameter. This indicates the result of coagulation, condensation, sedimentation, and transport and dilution processes: 2 months after the eruption there is a strong volcanic impact, but few submicrometer-size volcanic particles are left in the stratosphere 5 months after the eruption. The volcanic aerosol evolution is discussed further in Sect. 3.5.

Figure 6 shows the particle size distributions measured by the STAC, separated in $1 \mathrm{~km}$ layers of altitude, for the same four flights as Fig. 5, and compares these to size distributions simulated by the CESM1(WACCM) model. The size distributions are displayed in terms of number, surface, and volume, and should be read by pairs, comparing the STAC observations to the control run (volcano-off) on the one hand, and the simulations including the volcano eruption (volcanoon) on the other hand.

The figure highlights that the control run underestimates the particle number (area or volume) size distribution curves by orders of magnitude compared to the STAC observations. A much better agreement is found when the volcanic emission is included in the model simulations, showing a good ability of the model to reproduce volcanic aerosol plumes in terms of aerosol size distribution. For 18 May 2010, nearly 1 year after the eruption, the difference between the volcano-on simulation and control run is much less noticeable. This comparison reflects the ability of the model to simulate stratospheric aerosol size distributions in background (or near-background) conditions.

\subsection{Comparison of the model SAOD to OSIRIS observations}

Extinction data from OSIRIS have been used for model and observational assessment of stratospheric aerosol impacts following the Sarychev 2009 eruption (Haywood et al., 2010; Kravitz et al., 2011; O'Neill et al., 2012; Jégou et al., 2013). However, as mentioned in the introduction, biases in the 
(a)

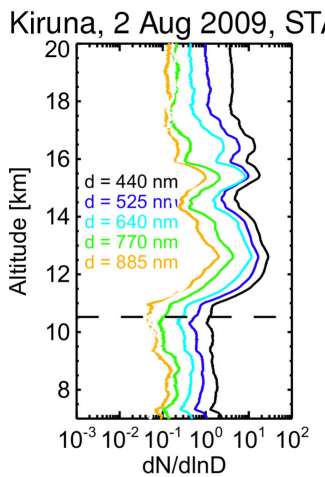

Kiruna, 7 Aug 2009, STAC

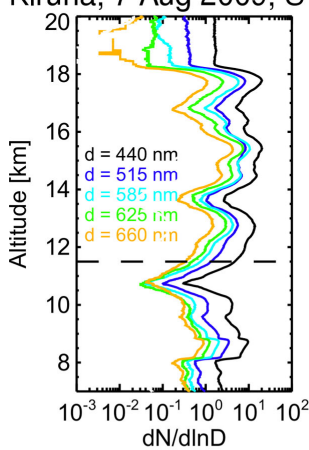

Kiruna, 18 Aug 2009, STAC

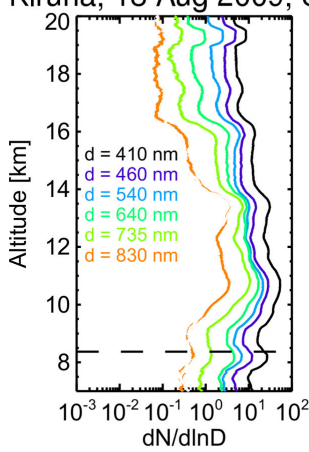

Kiruna, 18 May 2010, STAC

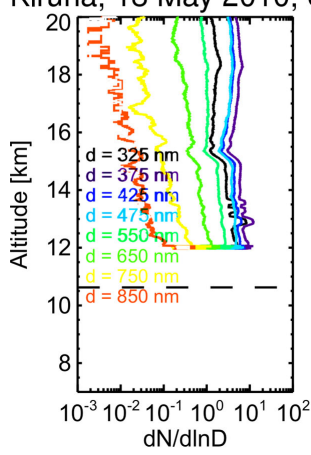

(b)

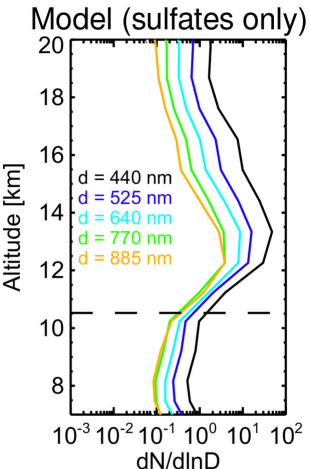

Model (sulfates only)
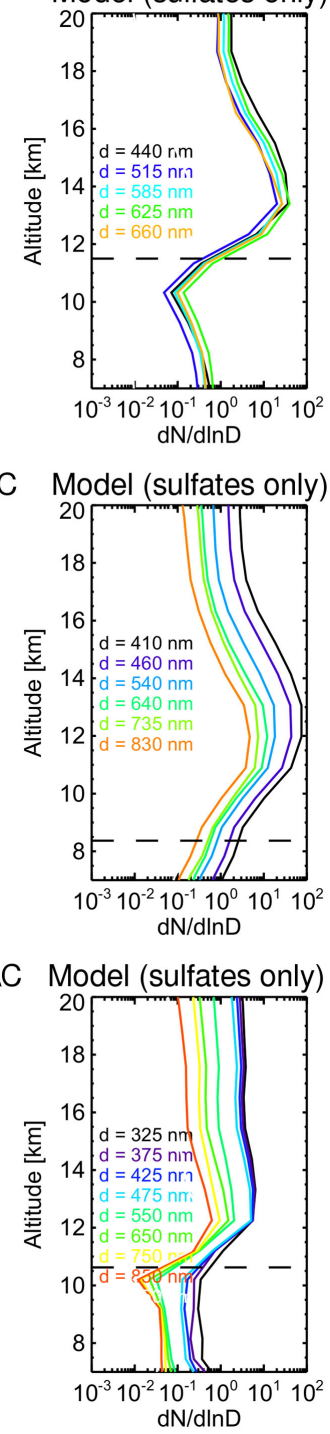

(c)
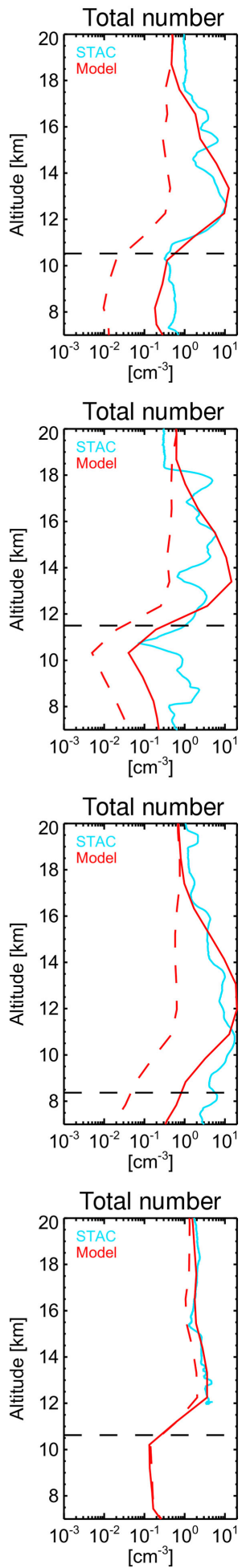

Figure 5. Comparison between STAC in situ measurements and CESM1(WACCM) simulations, over Kiruna, for 2, 7, and 18 August 2009 (plume detection), and 18 May 2010 (expected background conditions), and for altitudes ranging from 7 to $20 \mathrm{~km}$. (a) Particle counts operated by STAC, separated in size bins between 0.325 and $0.885 \mu \mathrm{m}$ diameter. (b) Simulated equivalent through the use of the CESM1(WACCM) model. (c) Comparison of the total particle counts for STAC and the model, over the STAC size range. The red dashed line shows results from the simulation without volcanic aerosols. Error on the STAC total counts can be evaluated to be $\pm 6 \%$. The model tropopause altitude computed is represented by the horizontal black dashed line. 


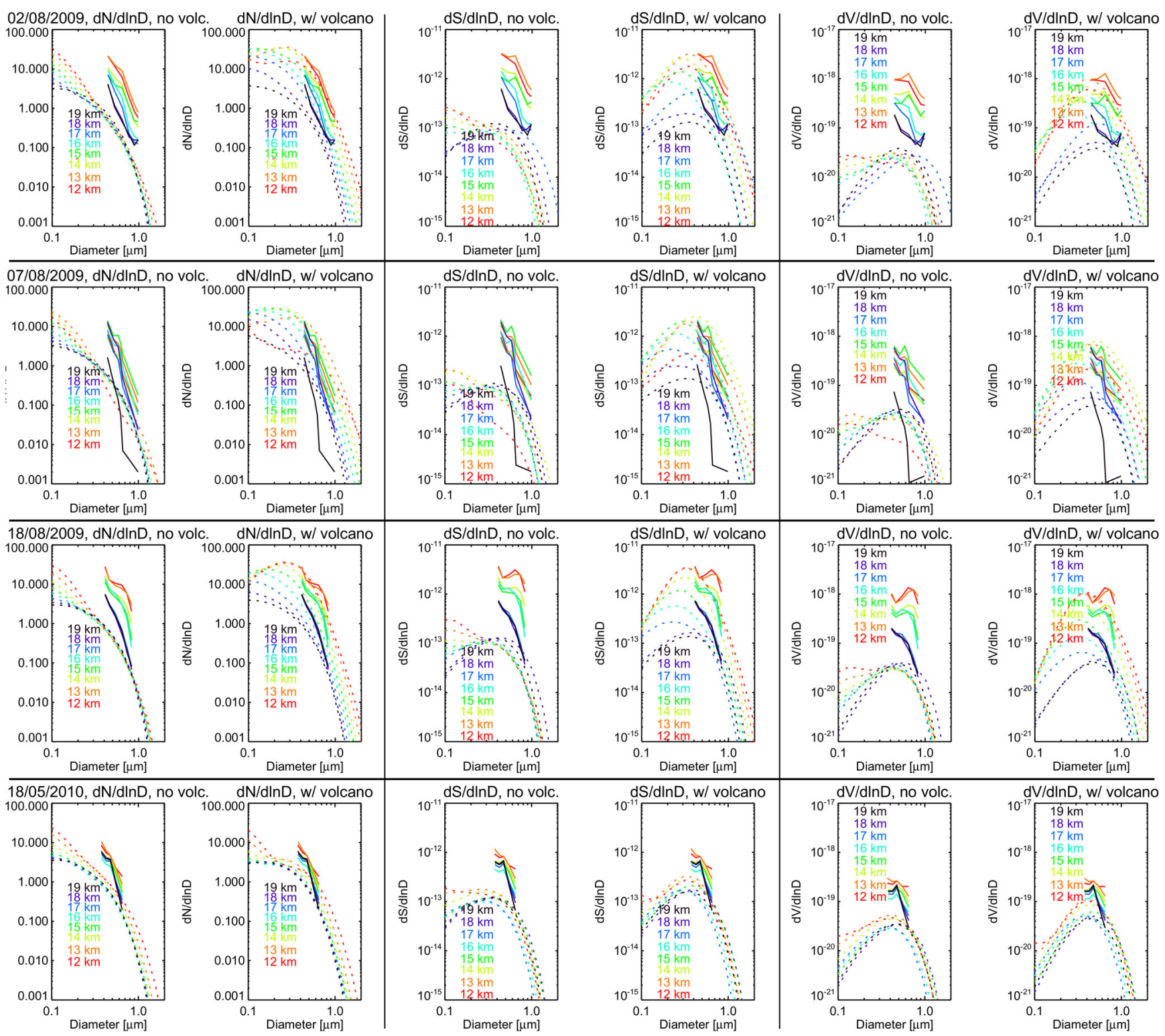

Figure 6. Particle size distributions in terms of number, area, and volume, separated for different altitude layers, shown for the same 4 days of interest already presented in Fig. 5. Size distributions observed by STAC are shown as solid lines and simulated by CESM1(WACCM) as dashed lines. Graphs go by adjacent pair: comparison of STAC data to both the volcano-off and the volcano-on cases highlights the improved agreement between model and measurements for simulations when the volcano is active. The measurement error on STAC measurements can be evaluated to be $\pm 6 \%$.

OSIRIS measurement following volcanic eruptions can affect the reported model-observation comparisons.

In Fromm et al. (2014), a detailed analysis of OSIRIS's limitations was carried out. These authors have shown that two main factors affect the derivation of SAOD by OSIRIS: (i) an upper detection limit on the value of extinctions, above which the measured values saturate, and (ii) a latitude dependence in the minimal altitude above which extinctions are integrated to yield the SAOD.
As pointed out by Fromm et al. (2014), it is impossible to reverse this process of data degradation; the best we can achieve to perform consistent model-to-observation comparisons is to degrade the extinctions derived from the model in order to derive SAOD "as OSIRIS would detect it". It must nonetheless be emphasized that such a comparison is not a complete evaluation of the model performance: any agreement found cannot fully validate aspects of the model output that are removed in the degradation process. Nevertheless, such a comparison of the degraded model to (biased) 


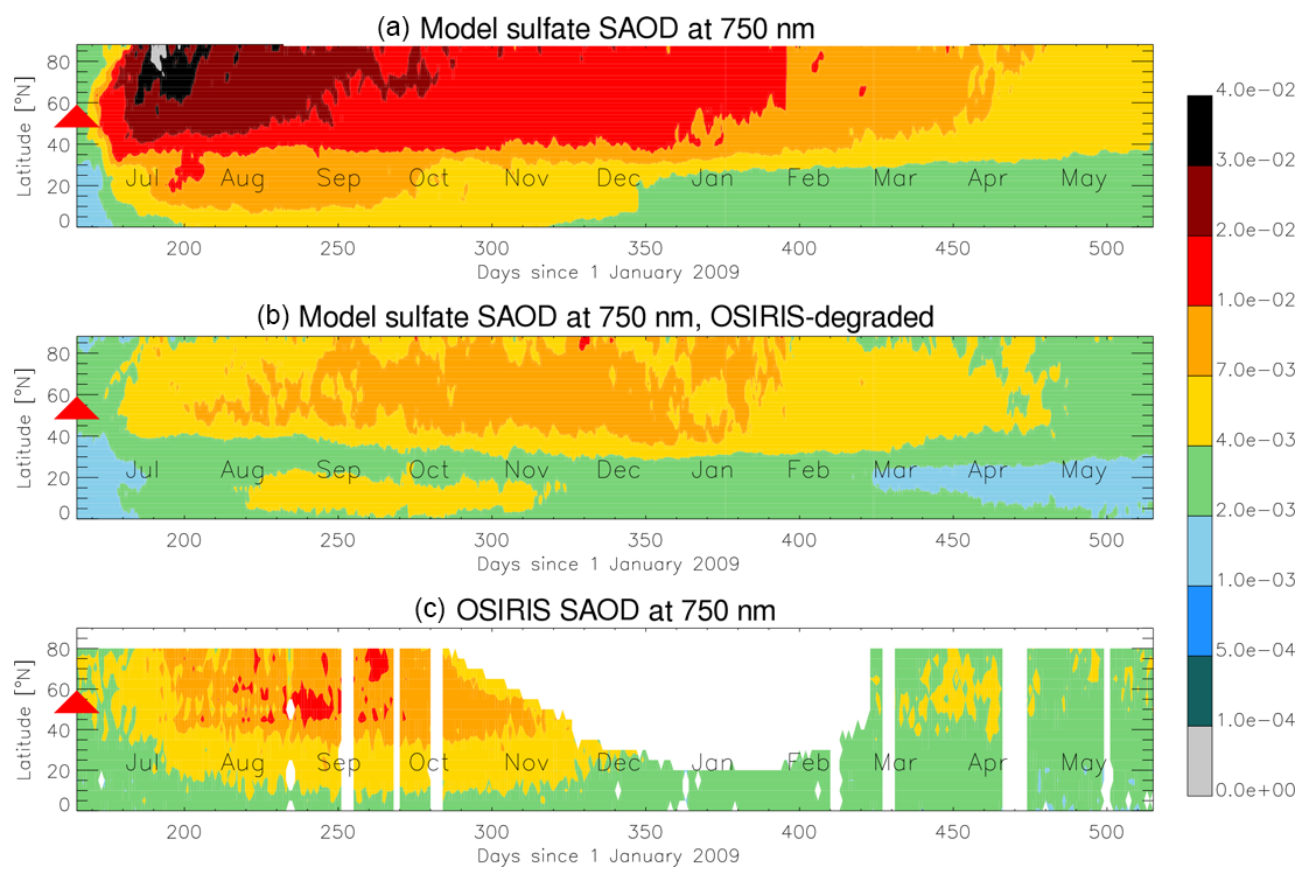

Figure 7. Comparison of modelled and observed stratospheric aerosol optical depth. (a) Stratospheric sulfate aerosol optical depth at $750 \mathrm{~nm}$ as simulated by CESM1(WACCM). (b) CESM1(WACCM)'s stratospheric sulfate AOD at $750 \mathrm{~nm}$ degraded to account for limitations in OSIRIS data (including saturation effect and minimum altitude). (c) Actual OSIRIS SAOD retrieval obtained from data with measurement limitations (see text for details).

satellite observations is highly valuable: it enables an assessment of model performance on a global scale, which cannot be achieved using local-scale in situ observations.

We use the following method: first, we allow the extinctions calculated in the model to saturate, with an upper threshold of $2.5 \times 10^{-3} \mathrm{~km}^{-1}$ corresponding to the detection limit described in Fromm et al. (2014). Second, extinctions are integrated over truncated vertical columns of the atmosphere, introducing a lower altitude limit dependent on the latitude and the local tropopause height. Following Fromm et al. (2014), we define the minimal altitudes $Z_{\min }$ above which the extinctions are integrated as

$Z_{\min }(\lambda, \phi, t)=Z_{\text {trop }}(\lambda, \phi, t)+\Delta(\phi)$,

where $Z_{\text {trop }}$ is the local tropopause height, $\lambda$ is longitude, $\phi$ is latitude, $t$ is time, and $\Delta$ is a positive offset function, which was taken in our case as linearly varying with latitude from $0.5 \mathrm{~km}$ at the Equator to $5.5 \mathrm{~km}$ at the poles. These were chosen as a trade-off between the histogram of values in Fromm et al. (2014) and actual minimum altitudes reached by OSIRIS over the 2009-2010 period (see Appendix Fig. A2). For this series of calculations, thermal tropopause heights were diagnosed in the model. We verify the broad consistency of these altitude limits for OSIRIS data during the 2009-2010 Sarychev post-eruption period in Fig. A2. Integrating the model-simulated saturated extinctions at $750 \mathrm{~nm}$ over the truncated altitude columns as defined above gives SAOD values that can be considered reasonably consistent with the measurements performed by OSIRIS.

Figure 7 a shows the zonally averaged stratospheric sulfate AOD, through time, over the Northern Hemisphere, as computed by CESM1(WACCM) in the volcano-on simulation (with co-injection of $\mathrm{HCl}$ ). A degradation of the model data was then performed following the method described above. The resulting estimation of the sulfate SAOD "as would be detected by OSIRIS" is shown in Fig. 7b. Figure 7c shows the observed SAOD measured by OSIRIS. Over the winter months, there is a lack of observational data from midOctober 2009 until the beginning of 2010, particularly at high latitudes, that coincides with the polar night. A precise comparison for these months is therefore not possible. CESM1(WACCM) suggests that the sulfate SAOD remains at a fairly constant level over the Northern Hemisphere over the October-December 2009 period, then decreases quite quickly from February to April 2010.

The degraded model SAOD shows reasonable agreement with the SAOD observed by OSIRIS, whilst the nondegraded model simulates much higher SAOD. This demonstrates that OSIRIS's limitations are crucial to the interpretation of its data. In Fig. 7, the observed (OSIRIS) SAOD shows, however, a slightly stronger maximal magnitude than the degraded SAOD from the model. A possible explanation may be that CESM1(WACCM) yields extinctions for sulfuric acid particulates only, whereas OSIRIS's observations ac- 


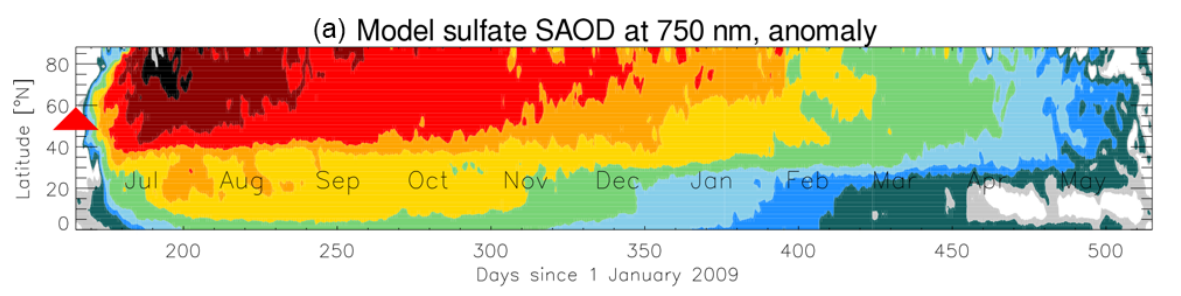

(b) Model sulfate SAOD at $750 \mathrm{~nm}$, OSIRIS-degraded, anomaly

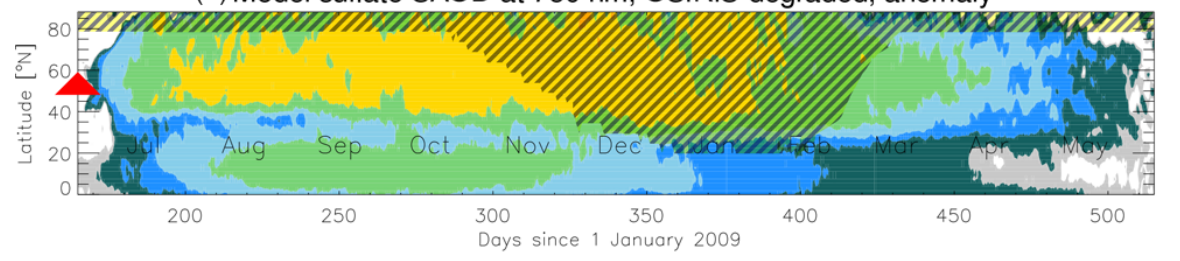

(c) OSIRIS SAOD at $750 \mathrm{~nm}$, anomaly

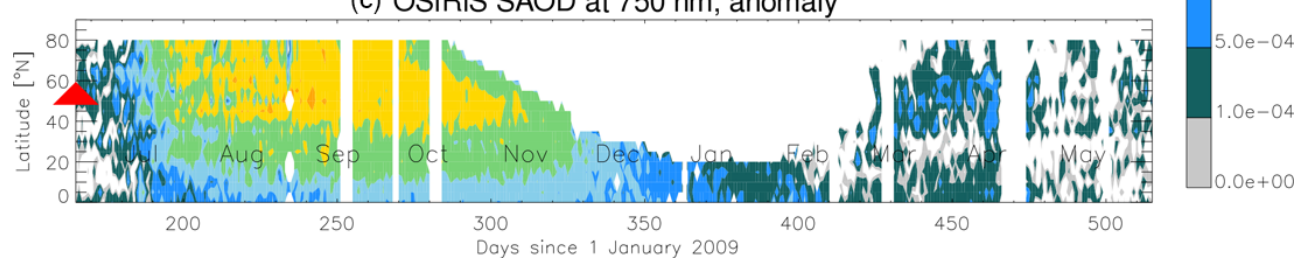

Figure 8. Comparison of modelled and observed anomalies in stratospheric aerosol optical depth. The absolute SAOD data from Fig. 7 have been converted to anomalies by subtracting modelled or observed SAOD 1 week before the eruption. (a) Stratospheric sulfate aerosol optical depth anomaly at $750 \mathrm{~nm}$ as simulated by CESM1(WACCM). (b) CESM1(WACCM)'s stratospheric sulfate SAOD anomaly at 750 nm degraded to account for limitations in OSIRIS data (including saturation effect and minimum altitude). (c) Actual anomaly in OSIRIS SAOD retrieval obtained from data with measurement limitations. The shaded area denotes the polar night, where OSIRIS's measurements are missing; see text for details.

count for a more comprehensive SAOD that can include nonsulfate compounds in the lower stratosphere.

To place a greater emphasis on sulfuric acid particulates due to the volcanic eruption, we convert all three data sets to anomalies. These anomalies were calculated by subtracting background conditions from the SAODs, for which averages calculated in the first week of June 2009 were used as an approximate reference. Figure 8 presents the same layout as Fig. 7 but now displays the SAOD anomalies over the same period (1 June 2009 until 31 May 2010). Again, a good accordance is found between the degraded model compared to OSIRIS (with the non-degraded model showing higher SAODs). The agreement in SAOD anomalies in Fig. 8 is better than for the absolute SAODs in Fig. 7. This indicates that differences in the background aerosol content prior to the eruption may explain some of the model-measurement discrepancy in terms of SAOD maximum amplitude as highlighted in Fig. 7.

Integrating anomaly data presented in Fig. 8 yields the Northern Hemisphere SAOD anomaly calculated at $750 \mathrm{~nm}$ over the year following the eruption, shown in Fig. 9. The dashed red line is SAOD simulated by the model. The plain red line indicates the same data after the OSIRIS bias degradation, and the blue line indicates SAOD from OSIRIS observations. Note that missing data in OSIRIS's measurements during winter were taken into account in the integration of the degraded model data, as shown by the shaded area in Fig. 8. Figure 8 along with Fig. 9 point out very clearly that taking into account OSIRIS's limitations gives a very good match between simulated and measured AOD values. Figure $9 \mathrm{~b}$ shows the modelled temporal evolution in $550 \mathrm{~nm}$ extinction coefficients, zonally averaged for the Northern Hemisphere, again highlighting maximum aerosol content around mid-July 2009.

Comparing the direct output of the model to OSIRIS in both Figs. 8 and 9 highlights a much stronger and faster formation of sulfuric acid aerosols in the model than can be detected by the OSIRIS instrument, which experiences strongest measurement biases shortly after the eruption due to the saturation effect. Further quantification is given below, including $e$-folding times.

Analysing the temporal evolution of the (non-degraded) model SAOD identifies a peak in the Northern Hemisphere $750 \mathrm{~nm}$ SAOD of $\approx 0.018$ on 12 July 2009 (Fig. 9), followed by a long decay with an $e$-folding time of $\approx 169$ days. Conversely, OSIRIS shows a much fainter and later peak $(\approx 0.004$ on 1 September 2009$)$, with a quicker decay (efolding time of 52 days). The degraded model SAOD yields an $e$-folding decay time (51 days) that is very comparable to that from OSIRIS; the peak value is also similar in amplitude to OSIRIS's and is reached on 17 October. This is slightly 
(a) Northern Hemisphere SAOD, at $750 \mathrm{~nm}$, anomaly

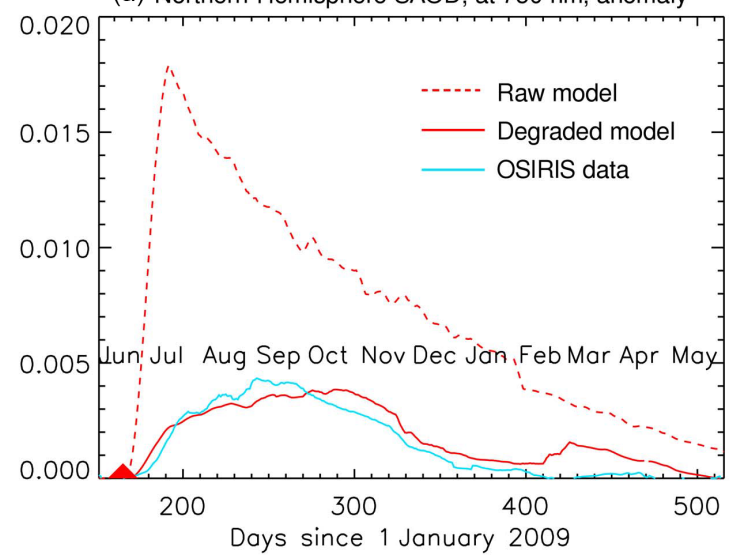

(b) Modelled extinction at $550 \mathrm{~nm}, \mathrm{~N} . \mathrm{H} ., \mathrm{SO}_{4}$, zonal average, anomaly

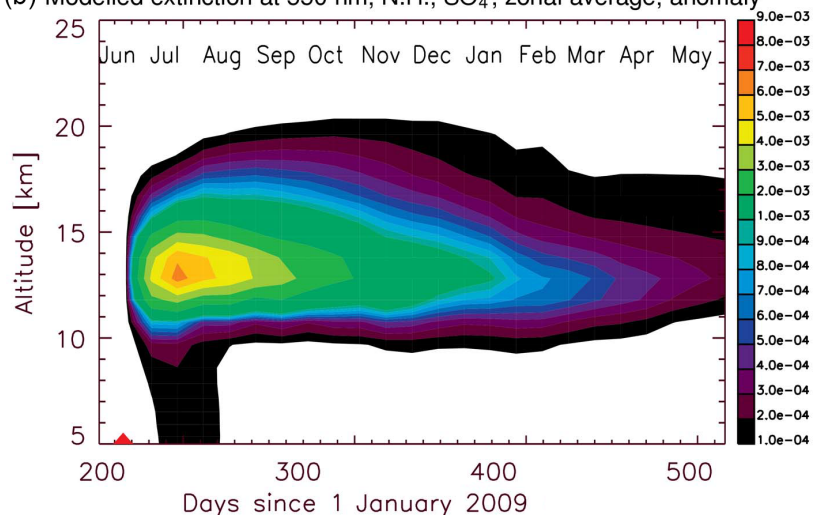

Figure 9. (a) Northern Hemisphere SAOD anomalies at $750 \mathrm{~nm}$ calculated by integrating the model-simulated extinction (dashed red line), then degraded (full red line), and comparison with OSIRIS's actual data (blue line). The Sarychev eruption is symbolized by the red triangle. (b) Modelled temporal evolution of the sulfuric acid aerosol extinction coefficient at $550 \mathrm{~nm}$, zonally averaged for the Northern Hemisphere, is displayed in anomaly (volcano-on minus volcano-off).

later than in the OSIRIS data, although the plateau in SAOD during that period can account for this delay.

Table 3 summarizes the SAOD $e$-folding times calculated in this study, along with values from previous studies (Haywood et al., 2010; Kravitz et al., 2011), and calculated using OSIRIS data. Different bands of latitude are explored. One can note that the $e$-folding times vary quite significantly between authors, including those computed from OSIRIS's data (it is likely that different versions of the OSIRIS data - v.5.05 up to v.5.07 for the present study - were used). The main point to be highlighted here is the fair consistency obtained between $e$-folding times computed on the CESM1(WACCM)'s degraded data and on OSIRIS retrievals in our study, as evident from the last two columns of Table 3. We find that both the saturation limit and the fact that extinction profiles may terminate well above the tropopause are significant sources of measurement bias that need to be taken into account in comparison of OSIRIS data to model studies.

\subsection{Post-eruption effective radius simulated using a sectional aerosol scheme}

Discrepancies in the magnitude and $e$-folding times between model and OSIRIS SAODs have been previously mentioned (e.g. Haywood et al. (2010); Kravitz et al. (2011); O'Neill et al. (2012)) and are summarized here in Table 3. This led to a consequent questioning of the models' reliability to simulate sulfuric acid particle formation accurately in terms of timing, thought to be caused by the absence of nucleation of new particles in the model (Haywood et al., 2010; Jégou et al., 2013). Conversely, our study using the CESM1(WACCM) model, whose aerosol microphysics includes nucleation, finds very good agreement with OSIRIS retrievals of SAOD in terms of magnitude and temporally when the model SAOD is degraded to account for both saturation and minimum altitude limitations on the SAOD derived from OSIRIS measurements. The maximum in our (non-degraded) model SAOD is significantly higher (by a factor of $\approx 4.5$ ) than estimated by both OSIRIS and earlier modelling studies of the 2009 Sarychev Peak eruption (Haywood et al., 2010). A key unconstrained parameter in these earlier studies was the stratospheric particle size distribution that exerts a strong influence on SAOD. It was set to yield an effective radius of around $r_{\text {eff }}=0.13-0.15 \mu \mathrm{m}$ in Haywood et al. (2010), with the model results from Kravitz et al. (2011) also adjusted to represent this size. Previous studies suggested higher $r_{\text {eff }}$ for large-magnitude eruptions that injected $\mathrm{SO}_{2}$ higher into the stratosphere (yielding longer-lived sulfate clouds): Russell et al. (1993) derived $r_{\text {eff }}$ of $0.22 \pm$ $0.06 \mu \mathrm{m}$ around 1 month after the Mt. Pinatubo 1991 eruption, whilst Stothers $(1997,2001)$ suggest post-eruption $r_{\text {eff }}$ grew from around $0.2-0.3$ to $0.4-0.5 \mu \mathrm{m}$ over the timescale of 1 year. Conversely, a lower $r_{\text {eff }}$ was thought to be reasonable for the moderate-magnitude 2009 Sarychev Peak eruption that injected into the lower stratosphere (yielding relatively fresh and shorter lived sulfate cloud), and appeared consistent with ground-based remote sensing at Mauna Loa (Hawaii, USA) (Barnes and Hofmann, 2001; Haywood et al., 2010).

Here, the sectional aerosol representation with full aerosol microphysics in CESM1(WACCM) enables to freely simulate the post-eruption evolution in particle size, without any a priori assumptions. Sulfuric acid is first produced by the oxidation of volcanic $\mathrm{SO}_{2}$, which leads to formation of new sulfuric acid particles by nucleation. Processes such as particle coagulation and condensation of sulfuric acid onto the existing particles causes particle growth. Particles are removed from the stratosphere by sedimentation and tropopause folding (Hamill et al., 1997). The balance between these processes determines the overall size distribution and its effective radius. Figure 10 shows the zonally averaged effective radius simulated by the model for three latitude bands ( 20 to 40,40 to 60 , and 60 to $80^{\circ} \mathrm{N}$ ). Particle growth occurs in regions with elevated sulfate concentrations following the vol- 
Table 3. SAOD $e$-folding times calculated for the model simulations and for OSIRIS's data reported in previous publications (Haywood et al., 2010; Kravitz et al., 2011) and in the present study. Different latitude bands are considered, and the decay times are all calculated considering SAOD values.

\begin{tabular}{lll|ll|lll}
\hline & \multicolumn{2}{l}{ Haywood et al. (2010) } & \multicolumn{2}{l}{ Kravitz et al. (2011) } & \multicolumn{2}{l}{ Present study with CESM1(WACCM) } \\
\cline { 2 - 7 } Latitude band & HadGEM2 & OSIRIS & ModelE & OSIRIS & Raw model & Degraded & OSIRIS \\
\hline 60 to $80^{\circ} \mathrm{N}$ & 60 days & 66 days & 57 days & 81 days & 99 days & 45 days & 41 days \\
40 to $60^{\circ} \mathrm{N}$ & 74 days & 75 days & 57 days & 147 days & 105 days & 45 days & 38 days \\
20 to $40^{\circ} \mathrm{N}$ & & & & & 120 days & 49 days & 31 days \\
0 to $20^{\circ} \mathrm{N}$ & & & 60 days & 408 days & 65 days & 41 days & 41 days \\
\hline Northern Hemisphere & 71 days & 81 days & & & 169 days & 51 days & 52 days \\
\hline
\end{tabular}

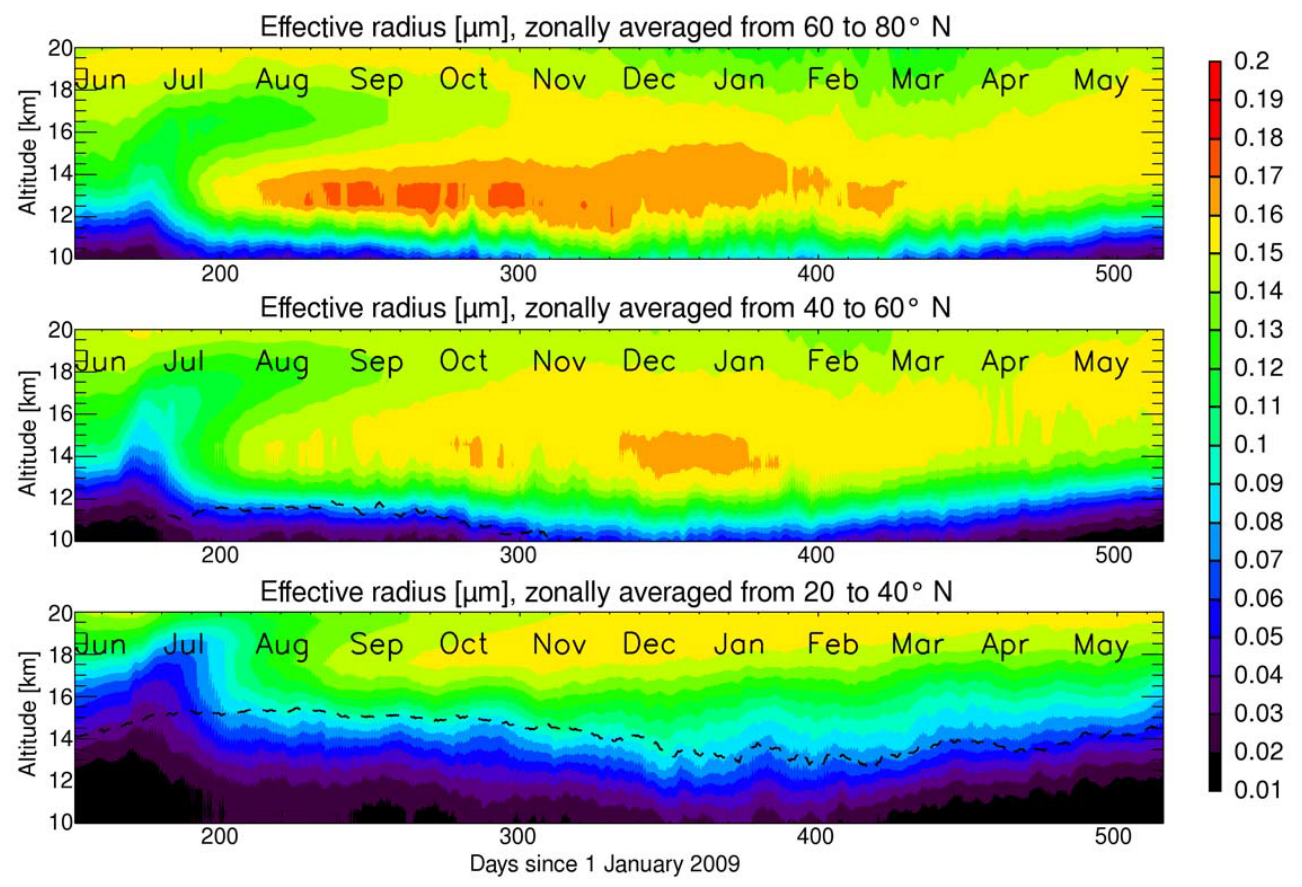

Figure 10. Zonally averaged effective radius simulated by CESM1(WACCM) model, in $\mu \mathrm{m}$, as a function of altitude for three latitude bands (20 to 40,40 to 60 , and 60 to $80^{\circ} \mathrm{N}$ ). The model tropopause is shown as a dashed line.

canic eruption (Fig. A3, Appendix). Particle size grows to reach a maximum in zonal mean $r_{\text {eff }}$ of up to $0.2 \mu \mathrm{m}$ in the lower stratosphere. The greatest enhancement in $r_{\text {eff }}$ occurs at high latitudes as expected given the poleward atmospheric transport in the stratosphere. At midlatitudes, a temporary decrease in $r_{\text {eff }}$ can also be seen immediately following the eruption: this is due to new particle formation (nucleation) of particles of a few nanometres' size. The latitudinal trend in $r_{\text {eff }}$ simulated by our model is broadly consistent with the trend reported from ground-based remote sensing at Eureka (Nunavut, Canada) that found $r_{\text {eff }}=0.29 \mu \mathrm{m}$ (O'Neill et al., 2012), and with ACE measurements, which report $r_{\text {eff }}=0.1-$ $0.3 \mu \mathrm{m}$ (Doeringer et al., 2012). Modelled absolute values of $r_{\text {eff }}$ are also globally consistent with balloon-borne observations in August 2009 (Jégou et al., 2013). Aerosol size or $r_{\text {eff }}$ exerts a strong influence on SAOD (e.g. Haywood et al.,
2010). A priori assumptions in stratospheric particle size are thus a major source of uncertainty in model studies that do not freely simulate the aerosol size evolution, and that will tend to cause an underestimation of SAOD in cases where the assumed $r_{\text {eff }}$ is lower than reality.

\subsection{Effects of $\mathrm{SO}_{2}$ and $\mathrm{HCl}$ co-injection on stratospheric chemistry}

Most studies investigating the impacts of modern-day eruptions on stratospheric chemistry have focused on the role of sulfuric acid particles in reducing $\mathrm{NO}_{x}$ levels and activating pre-existing chlorine and bromine $\left(\mathrm{ClO}_{x}, \mathrm{BrO}_{x}\right)$ in the stratosphere (Fahey et al., 1993; Solomon, 1999). One must note that halogens from the $1991 \mathrm{Mt}$. Pinatubo eruption were efficiently washed out and therefore did not reach 

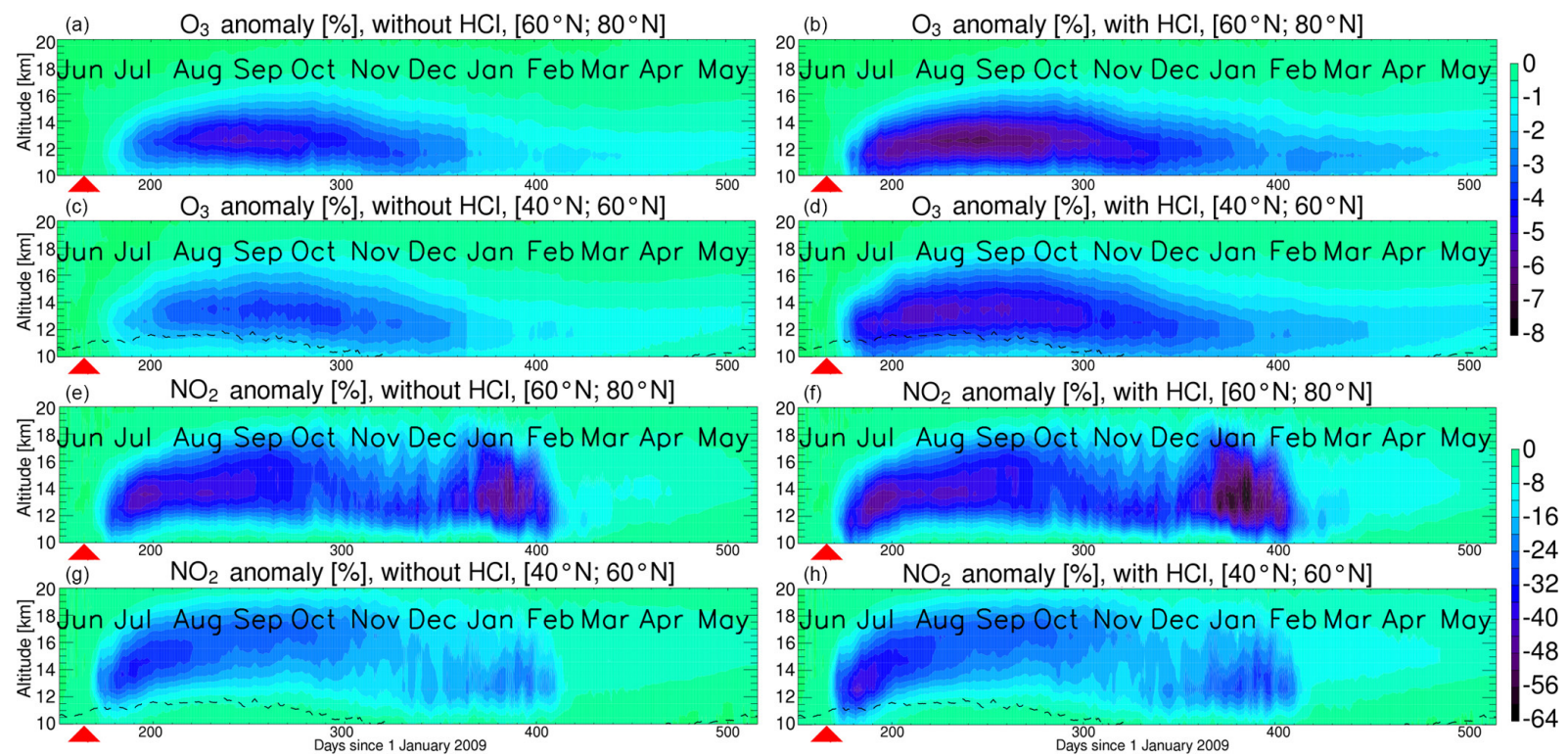

Figure 11. Zonally averaged depletions in stratospheric ozone and $\mathrm{NO}_{2}$ at midlatitudes (40 to $60^{\circ} \mathrm{N}$ ) and high latitudes $\left(60\right.$ to $80^{\circ} \mathrm{N}$ ) following the Sarychev eruption. Ozone is shown in the upper set of plots, $\mathrm{NO}_{2}$ in the lower sets; within each pair, the latitudes are shown as 60 to $80^{\circ} \mathrm{N}$ (upper plot of the pair) and 40 to $60^{\circ} \mathrm{N}$ (lower plot of the pair). Simulations by the CESM1(WACCM) model are expressed as percentage anomalies (with respect to the volcano-off control run) and are calculated for the simulation with $\mathrm{SO}_{2}$ injection only (a, c, e, g), and simulation with co-injection of $\mathrm{HCl}(\mathbf{b}, \mathbf{d}, \mathbf{f}, \mathbf{h})$. Impacts on stratospheric chemistry are greater at higher latitudes and are enhanced by co-injection of volcanic $\mathrm{HCl}$.

the stratosphere (Mankin et al., 1992; Tabazadeh and Turco, 1993), though the washout for the Sarychev case was not necessarily as efficient (von Glasow et al., 2009). Observational evidence of stratospheric $\mathrm{NO}_{2}$ depletion following moderate-magnitude volcanic eruptions is provided by Adams et al. (2017) based on satellite remote sensing, and Berthet et al. (2017) by balloon-borne observations following the Sarychev Peak eruption. Our study builds on these recent works in two aspects. First, we use the CESM1(WACCM) model with sectional aerosol representation. We freely simulate the aerosol surface area (SAD) (a function of particle number and size) that is a key control on stratospheric chemistry impacts. Second, we investigate the stratospheric chemistry influence of volcanic $\mathrm{HCl}$ that observations show was co-injected alongside $\mathrm{SO}_{2}$ (Carn et al., 2016). The simulated anomalies in ozone and $\mathrm{NO}_{2}$ for the latitudinal bands 40 to 60 and 60 to $80^{\circ} \mathrm{N}$ are shown for simulations with $\mathrm{SO}_{2}$ injection only, and for $\mathrm{HCl}$ co-injection with $\mathrm{SO}_{2}$ in Fig. 11 . In summer, greater depletions of up to $-60 \%$ for $\mathrm{NO}_{2}$ are found at higher latitudes. This is primarily due to the higher aerosol loadings in these regions, and to favourable solar illumination conditions for which the catalytic ozone loss cycles (through $\mathrm{OH}$ radical production) are enhanced (Berthet et al., 2017). A more detailed description of the involved chemical processes is provided in Berthet et al. (2017).

Our results are broadly consistent with the observations of Adams et al. (2017), who reported that stratospheric $\mathrm{NO}_{2}$ abundances were reduced by up to $\approx 45-55 \%$ over $40-80^{\circ} \mathrm{N}$ as consequence of the Sarychev eruption. Berthet et al. (2017) showed maximum $\mathrm{NO}_{2}$ depletion of $\approx 50 \%$ in the summertime lower stratosphere above Kiruna (Sweden) following the Sarychev eruption, based on REPROBUS model simulations with SAD prescribed from observations and without $\mathrm{HCl}$ injection. They predicted that ozone depletion reached up to $4 \%$ in the lowermost stratosphere in summertime/early fall. Our CESM1(WACCM) simulation with a sectional aerosol scheme and injection of volcanic $\mathrm{SO}_{2}$ (only) finds similar high-latitude maximum $\mathrm{NO}_{2}$ reduction $(\approx 50 \%)$ and maximum ozone depletion (5\%). Interestingly, our simulations suggest somewhat greater maximum depletions in the simulation with co-injected volcanic $\mathrm{HCl}$ (7 and $60 \%$, for ozone and $\mathrm{NO}_{2}$, respectively) compared to the simulation with $\mathrm{SO}_{2}$ injection only (5 and $50 \%$, for ozone and $\mathrm{NO}_{2}$, respectively). As a result of the enhanced stratospheric $\mathrm{HCl}$ budget throughout the season, more ozone-depleting chlorine radicals are expected to be formed due to Reaction (R1) even at midlatitude conditions, though the impact on ozone appears limited. The impact on summer and fall $\mathrm{NO}_{2}$ is negligible. In the polar winter, cold temperatures lead to further chlorine activation through heterogeneous processes enhancing some $\mathrm{NO}_{x}$ and ozone reduction. This study highlights the potential for volcanic $\mathrm{HCl}$ to complement and enhance $\mathrm{SO}_{2}$-sulfate impacts on stratospheric chemistry, for eruptions where there is a significant $\mathrm{HCl}$ injection to high altitudes. The influence of Sarychev Peak eruption on stratospheric chemistry is nevertheless relatively modest, due to 
the moderate eruption size, in terms of both the $\mathrm{SO}_{2}$ and $\mathrm{HCl}$ injected amounts.

\section{Conclusions}

We have presented a series of simulations carried out with the CESM1(WACCM) model for the study of stratospheric chemical impacts from the moderate-magnitude 2009 Sarychev eruption. Associated with the CARMA module, the model explicitly simulates the aerosol size evolution using a sectional aerosol scheme (across 30 size bins) and includes detailed aerosol microphysics. To simulate the eruption, we assumed a $0.9 \mathrm{Tg}$ injection of sulfur dioxide between 11 and $15 \mathrm{~km}$ altitude over 1 day of eruption (15 June 2009). We also investigated the impacts of co-injected volcanic $\mathrm{HCl}$.

Through comparison of the model results with satellite (IASI) retrievals of $\mathrm{SO}_{2}$ and in situ measurements of stratospheric aerosols, we were able to assess the model performance, finding good agreement in terms of plume dispersion (Fig. 1) and particle formation rates (Figs. 2, 3), particle number concentrations as well as particle size distributions before and following the eruption (Figs. 4, 5, 6). In particular, very good agreement was found in terms of particle number concentrations and particle size distributions obtained from balloon-borne observations over Kiruna (northern Sweden) in July-August 2009 (Figs. 5, 6) and Laramie (Wyoming, USA) in November 2009 (Fig. 4), confirming the strong impact of the volcanic eruption on the stratospheric aerosol particle load. This suggests that particle formation is represented well in the sectional aerosol scheme (CARMA) in CESM1(WACCM). The simulations suggest that the effective radius $\left(r_{\text {eff }}\right)$ becomes enhanced following the eruption reaching up to $0.2 \mu \mathrm{m}$ in the zonal average. This is larger than the fixed aerosol size assumed in previous model studies with limited aerosol microphysics, e.g. $r_{\text {eff }}=0.13-0.15 \mu \mathrm{m}$ (Haywood et al., 2010).

The lack of more resolved data might be a source of uncertainty on the injection altitudes. However, this overall quantitative agreement reflects the model performance in $\mathrm{SO}_{2}$ oxidation, atmospheric dispersion, and aerosol processing. It indicates a suitable choice of eruption source parameters as used in previous studies, e.g. Haywood et al. (2010) (an injection altitude ranging from 11 to $15 \mathrm{~km}$ for $\mathrm{SO}_{2}$, a vertical even spread of the total mass of gases injected, and a sole injection of the total gas mass on 15 June 2009, neglecting other minor injections on other days). These eruption source parameters did provide good results. They might need to be refined for model studies at higher temporal or spatial resolution; see Wu et al. (2017); Günther et al. (2017). We point out that an injected mass of $0.9 \mathrm{Tg} \mathrm{SO}_{2}$ (Clarisse et al., 2012; Realmuto and Berk, 2016) instead of $1.2 \mathrm{Tg}$ of previous studies, e.g. Haywood et al. (2010), is a fair hypothesis, and enables the model to closely reproduce the observed $\mathrm{SO}_{2}$ burden according to the IASI retrievals of Clarisse et al. (2012).
In addition, we investigated the co-injection of volcanic $\mathrm{HCl}$ to the stratosphere. Our simulations are based on the reported stratospheric $\mathrm{HCl} / \mathrm{SO}_{2}$ mass ratio of 0.03 for Sarychev Peak eruption, according to analysis of satellite data by Carn et al. (2016). The altitude and timing of the $\mathrm{HCl}$ injection in the model were assumed to be identical to the $\mathrm{SO}_{2}$ injection. Our study suggests that the presence of $\mathrm{HCl}$ leads to a delay in the oxidation of $\mathrm{SO}_{2}$ to form sulfuric acid particles of about 2 days, with a 5-10\% increase in the modelled $e$-folding times for $\mathrm{SO}_{2}$. We also find a better temporal accordance in $\mathrm{SO}_{2}$ burden derived from satellite (IASI) data and our simulations when taking $\mathrm{HCl}$ into account. The additional surface area provided by volcanic particles catalyses reactions that can perturb stratospheric chemistry, including activation of stratospheric halogens, and can lead to strong reduction of $\mathrm{NO}_{2}$ and modest depletion of ozone as highlighted by Berthet et al. (2017) for Sarychev Peak. Our simulations show that the co-injected volcanic $\mathrm{HCl}$ also affects the post-eruption stratospheric chemistry of ozone and $\mathrm{NO}_{x}$, depleting these species more severely than in simulations that account for $\mathrm{SO}_{2}$ injections only. Our results highlight that volcanic $\mathrm{HCl}$ emissions should be taken into account when simulating sulfur chemistry and stratospheric chemistry impacts from volcanic eruptions during which $\mathrm{HCl}$ is co-injected.

The second major point highlighted by this paper is the treatment of limitations in SAOD derived from OSIRIS measurements: both a saturation effect and a varying minimum altitude in available OSIRIS data (i.e. extinction profiles may terminate well above the tropopause, in particular at high latitudes) were identified by Fromm et al. (2014). We used a two-step model degradation process to reproduce these biases in the modelled data and found as a result very good agreement with the actual OSIRIS measurements following the volcanic eruption, reproducing both the magnitude and temporal evolution of the SAOD following the 2009 Sarychev eruption (Figs. 7, 8, 9, Table 3). Recent studies (Haywood et al., 2010; Kravitz et al., 2011; O'Neill et al., 2012) quantifying volcanic impacts tended to (only) incriminate their models' particle formation schemes because the comparisons with OSIRIS's satellite retrievals were poor specifically regarding the timing of the SAOD maximum. As a matter of fact, caveats on OSIRIS's measurement, as outlined by Fromm et al. (2014), are the key point to any model-observation comparison. We show that there is a considerably improved match between simulated and observed SAODs when these are taken into account. Once again, we stress that this agreement is only obtained by degrading the model output to account for OSIRIS's caveats; the fact that Figs. 8 and 9 show similar anomaly values cannot be sufficient to thoroughly validate the modelled SAODs through time. Rather, they provide supportive evidence to our study of stratospheric aerosol evolution following the Sarychev Peak 2009 eruption, using a model with detailed aerosol microphysics and sectional aerosol representation. The non- 
degraded output from our model shows substantially higher SAOD (maximum of 0.018 at $750 \mathrm{~nm}$ ) than observed by OSIRIS (0.004), or as reported by previous model studies (with fixed aerosol size and limited microphysics). Our study therefore highlights that previous modelling studies (involving assumptions on particle size) that reported agreement with (biased) post-eruption estimates of SAOD derived from OSIRIS likely underestimated the climate impact of the 2009 Sarychev Peak eruption.
Data availability. Balloon data for STAC can be accessed on the ESPRI database (ESPRI Data Centre, 2017; https://cds-espri.ipsl. upmc.fr). 


\section{Appendix A}

(a) Sulfate anomaly $\left[\mathrm{kg} \cdot \mathrm{kg}^{-1}\right]$ at $13 \mathrm{~km}$ altitude, 22 June 2009

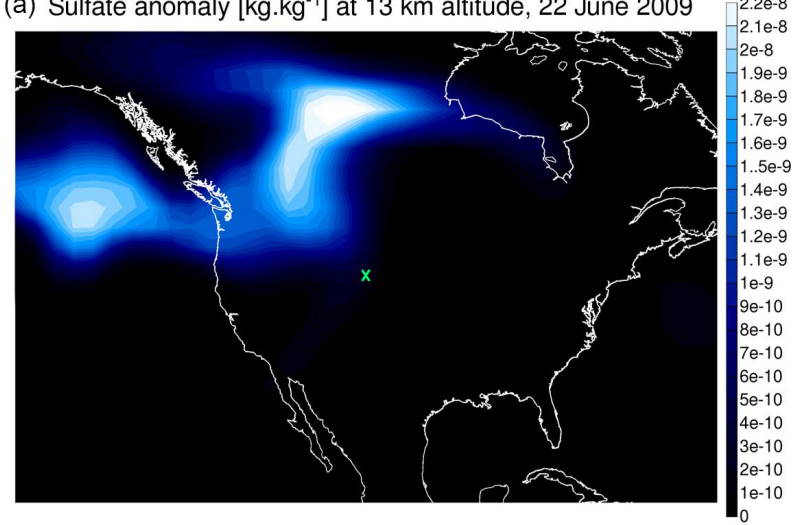

(b) Sulfate anomaly [kg.kg-1] at $13 \mathrm{~km}$ altitude, 7 November $2009{ }^{1.6 e-9}$

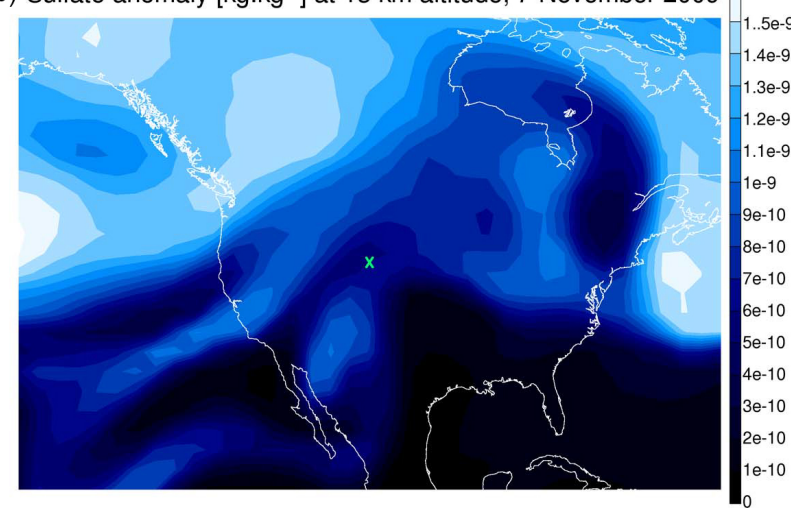

Figure A1. Geographic map over the USA displaying the simulated sulfate aerosol anomaly at $13 \mathrm{~km}$ altitude on 22 June 2009 (a) and 7 November 2009 (b), as computed by CESM1(WACCM). Note the order of magnitude difference in colour scale between the two plots. Laramie is indicated by the green cross: it is located on the very edge of a modelled aerosol plume structure on 22 June 2009 but below a more widespread (and dilute) plume on 7 November 2009.

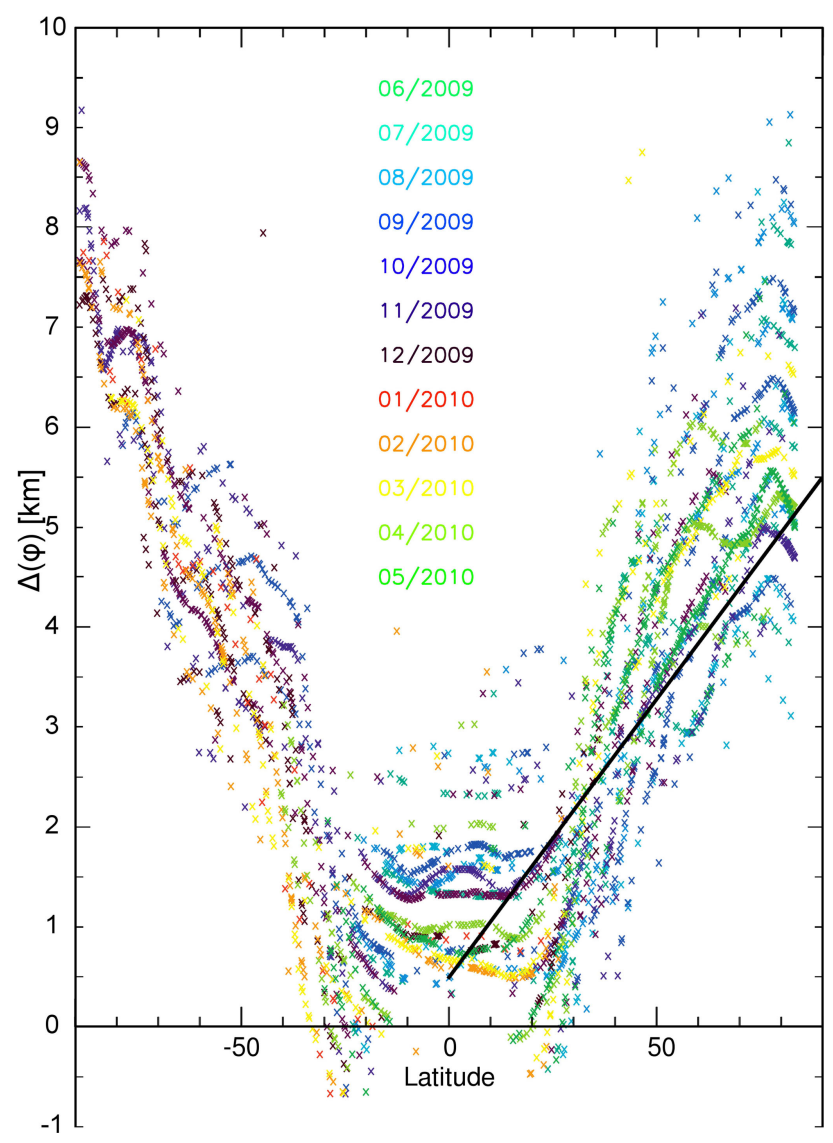

Figure A2. Minimum altitude of OSIRIS extinction data calculated as an offset relative to the model tropopause as a function of latitude. OSIRIS data are shown for the first of every month from June 2009 to May 2010, with different colours depending on the month considered. There are some missing data during the winter in each hemisphere, particularly at high latitudes. The solid line shows the latitude dependence of the minimum altitude threshold assumed in the model degradation in this study. 


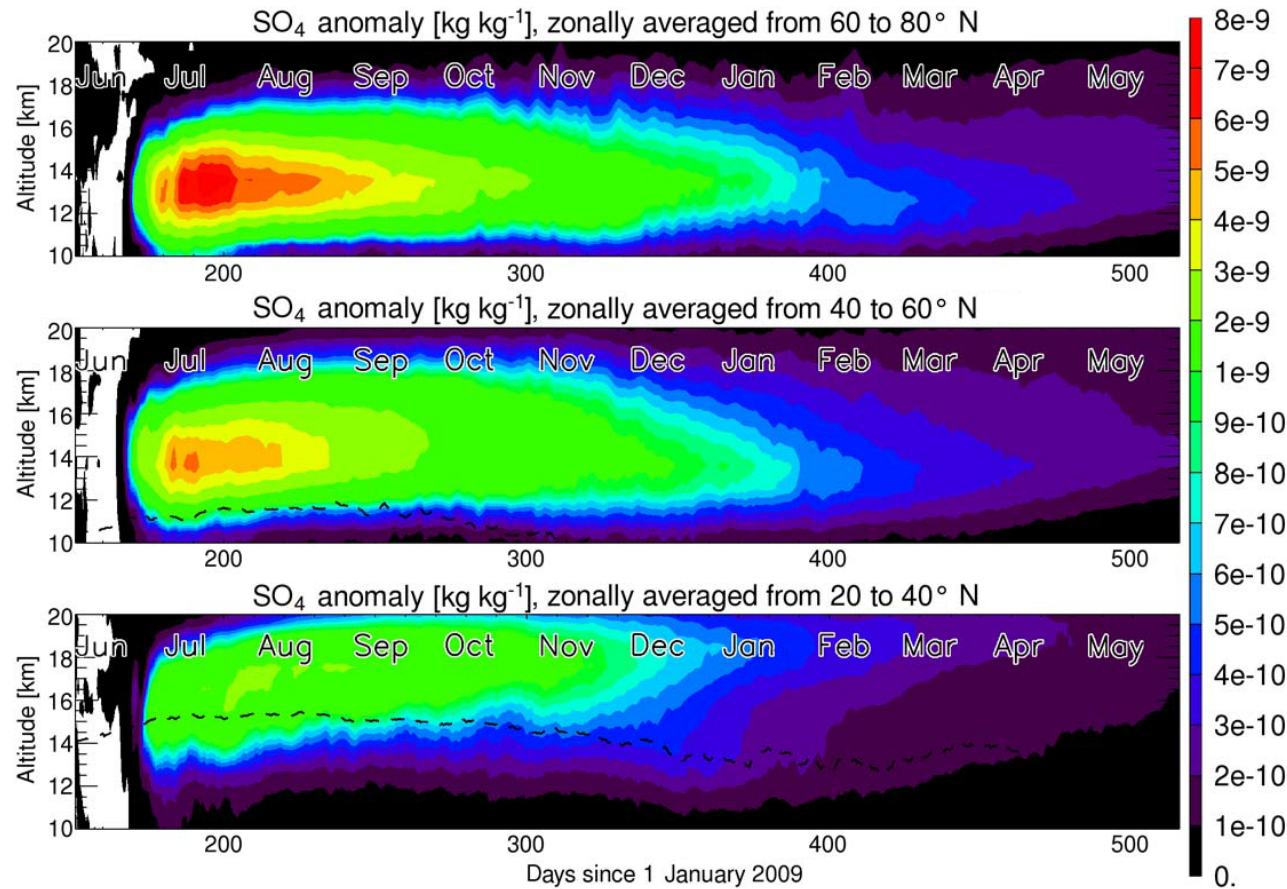

Figure A3. Zonally averaged sulfate anomaly, in $\mathrm{kg} \mathrm{kg}^{-1}$, as simulated by the CESM1(WACCM) model as a function of altitude for three latitude bands ( 20 to 40,40 to 60 , and 60 to $80^{\circ} \mathrm{N}$ ). The model tropopause is shown as a dashed line. 
Competing interests. The authors declare that they have no conflict of interest.

Acknowledgements. This work was undertaken as part of WP7 of the VOLTAIRE LabEx (VOLatils - Terre, Atmosphère et Interactions - Ressources et Environnement), convention number ANR10-LABX-100-01.

The authors wish to thank the technical staff of the CaSciModOT structure (Calcul Scientifique et Modélisation Orléans-Tours), part of the French national network of complex systems (RNSC - Réseau National des Systèmes Complexes), along with the CINES (Centre Informatique National de l'Enseignement Supérieur), thanks to which the simulations could be completed. This work was granted access to the high-performance computing (HPC) resources of CINES under the 2014 allocation (c2014019129) made by GENCI.

The authors are grateful to the "Centre National d'Études Spatiales" (CNES) balloon launching team for successful operations and to the Swedish Space Corporation at Esrange. The StraPolÉté project has been funded by the French "Agence Nationale de la Recherche" (ANR-BLAN08-1-31627), CNES, and the "Institut Polaire Paul-Émile Victor" (IPEV). The 2010 balloon observations in the frame of the AEROWAVE project have been supported by the French CNRS-INSU Balloon Committee (CSTB).

The ESPRI-AERIS (formerly ETHER) database (CNESINSUCNRS) and the CNES "sous-direction ballon" are partners of the project.

The authors also would like to thank the NCAR/CESM online discussion board for many helpful technical discussions that helped throughout this study, along with Charles G. Bardeen from NCAR for some discussion about the model, Sophie Bouffiès-Cloché from IPSL for providing the MERRA forcing data, Adam Bourassa from University of Saskatchewan for some discussion about OSIRIS data, and Terry Deshler for providing the Wyoming OPC data.

Lieven Clarisse is a research associate (Chercheur Qualifié) with the Belgian F.R.S.-FNRS.

Edited by: Farahnaz Khosrawi

Reviewed by: three anonymous referees

\section{References}

Adams, C., Bourassa, A. E., McLinden, C. A., Sioris, C. E., von Clarmann, T., Funke, B., Rieger, L. A., and Degenstein, D. A.: Effect of volcanic aerosol on stratospheric $\mathrm{NO}_{2}$ and $\mathrm{N}_{2} \mathrm{O}_{5}$ from 2002-2014 as measured by Odin-OSIRIS and Envisat-MIPAS, Atmos. Chem. Phys., 17, 8063-8080, https://doi.org/10.5194/acp-17-8063-2017, 2017.

Ammann, C. M., Meehl, G. A., Washington, W. M., and Zender, C. S.: A monthly and latitudinally varying volcanic forcing dataset in simulations of 20th century climate, Geophys. Res. Lett., 30, 1657, https://doi.org/10.1029/2003GL016875, 2003.

Andersson, S. M., Martinsson, B. G., Vernier, J.-P., Friberg, J., Brenninkmeijer, C. A. M., Hermann, M., van Velthoven, P. F. J., and Zahn, A.: Significant radiative impact of volcanic aerosol in the lowermost stratosphere, Nat. Commun., 6, 7692, https://doi.org/10.1038/ncomms8692, 2015.
Barnes, J. E. and Hofmann, D. J.: Variability in the stratospheric background aerosol over Mauna Loa Observatory, Geophys. Res. Lett., 28, 2895-2898, https://doi.org/10.1029/2001GL013127, 2001.

Berthet, G., Jégou, F., Catoire, V., Krysztofiak, G., Renard, J.-B., Bourassa, A. E., Degenstein, D. A., Brogniez, C., Dorf, M., Kreycy, S., Pfeilsticker, K., Werner, B., Lefèvre, F., Roberts, T. J., Lurton, T., Vignelles, D., Bègue, N., Bourgeois, Q., Daugeron, D., Chartier, M., Robert, C., Gaubicher, B., and Guimbaud, C.: Impact of a moderate volcanic eruption on chemistry in the lower stratosphere: balloon-borne observations and model calculations, Atmos. Chem. Phys., 17, 2229-2253, https://doi.org/10.5194/acp-17-2229-2017, 2017.

Beyer, K. D., Ravishankara, A. R., and Lovejoy, E. R.: Measurements of $\mathrm{UV}$ refractive indices and densities of $\mathrm{H}_{2} \mathrm{SO}_{4} / \mathrm{H}_{2} \mathrm{O}$ and $\mathrm{H}_{2} \mathrm{SO}_{4} / \mathrm{HNO}_{3} / \mathrm{H}_{2} \mathrm{O}$ solutions, J. Geophys. Res., 101, 14519 14524, https://doi.org/10.1029/96JD00937, 1996.

Bluth, G. J., Doiron, S. D., Schnetzler, C. C., Krueger, A. J., and Walter, L. S.: Global tracking of the $\mathrm{SO}_{2}$ clouds from the June, 1991 Mount Pinatubo eruptions, Geophys. Res. Lett., 19, 151154, https://doi.org/10.1029/91GL02792, 1992.

Bourassa, A. E., Degenstein, D. A., Gattinger, R. L., and Llewellyn, E. J.: Stratospheric aerosol retrieval with optical spectrograph and infrared imaging system limb scatter measurements, J. Geophys. Res.-Atmos., 112, D10217, https://doi.org/10.1029/2006JD008079, 2007.

Bourassa, A. E., Degenstein, D. A., and Llewellyn, E. J.: Retrieval of stratospheric aerosol size information from OSIRIS limb scattered sunlight spectra, Atmos. Chem. Phys., 8, 63756380, https://doi.org/10.5194/acp-8-6375-2008, 2008.

Brogniez, C., Huret, N., Eckermann, S., Rivière, E. D., Pirre, M., Herman, M., Balois, J.-Y., Verwaerde, C., Larsen, N., and Knudsen, B.: Polar stratospheric cloud microphysical properties measured by the microRADIBAL instrument on 25 January 2000 above Esrange and modeling interpretation, J. Geophys. Res.-Atmos., 108, 8332-8343, https://doi.org/10.1029/2001JD001017, 2003.

Carboni, E., Grainger, R. G., Mather, T. A., Pyle, D. M., Thomas, G. E., Siddans, R., Smith, A. J. A., Dudhia, A., Koukouli, M. E., and Balis, D.: The vertical distribution of volcanic $\mathrm{SO}_{2}$ plumes measured by IASI, Atmos. Chem. Phys., 16, 4343-4367, https://doi.org/10.5194/acp-16-4343-2016, 2016.

Carn, S. A., Clarisse, L., and Prata, A. J.: Multidecadal satellite measurements of global volcanic degassing, J. Volcanol. Geoth. Res., 311, 99-134, https://doi.org/10.1016/j.jvolgeores.2016.01.002, 2016.

Clarisse, L., Coheur, P. F., Prata, A. J., Hurtmans, D., Razavi, A., Phulpin, T., Hadji-Lazaro, J., and Clerbaux, C.: Tracking and quantifying volcanic $\mathrm{SO}_{2}$ with IASI, the September 2007 eruption at Jebel at Tair, Atmos. Chem. Phys., 8, 7723-7734, https://doi.org/10.5194/acp-8-7723-2008, 2008.

Clarisse, L., Hurtmans, D., Clerbaux, C., Hadji-Lazaro, J., Ngadi, Y., and Coheur, P.-F.: Retrieval of sulphur dioxide from the infrared atmospheric sounding interferometer (IASI), Atmos. Meas. Tech., 5, 581-594, https://doi.org/10.5194/amt-5-5812012, 2012.

Deshler, T., Hervig, M. E., Hofmann, D. J., Rosen, J. M., and Liley, J. B.: Thirty years of in situ stratospheric aerosol size distribution measurements from Laramie, Wyoming $\left(41^{\circ} \mathrm{N}\right)$, using 
balloon-borne instruments, J. Geophys. Res.-Atmos., 108, 4167, https://doi.org/10.1029/2002JD002514, 2003.

Diehl, T., Heil, A., Chin, M., Pan, X., Streets, D., Schultz, M., and Kinne, S.: Anthropogenic, biomass burning, and volcanic emissions of black carbon, organic carbon, and $\mathrm{SO}_{2}$ from 1980 to 2010 for hindcast model experiments, Atmos. Chem. Phys. Discuss., 12, 24895-24954, https://doi.org/10.5194/acpd-12-248952012, 2012.

Doeringer, D., Eldering, A., Boone, C. D., Abad, G. G., and Bernath, P. F.: Observation of sulfate aerosols and $\mathrm{SO}_{2}$ from the Sarychev volcanic eruption using data from the Atmospheric Chemistry Experiment (ACE), J. Geophys. Res.-Atmos., 117, D03203, https://doi.org/10.1029/2011JD016556, 2012.

Douglass, D. H. and Knox, R. S.: Climate forcing by the volcanic eruption of Mount Pinatubo, Geophys. Res. Lett., 32, L05710, https://doi.org/10.1029/2004GL022119, 2005.

English, J. M., Toon, O. B., Mills, M. J., and Yu, F.: Microphysical simulations of new particle formation in the upper troposphere and lower stratosphere, Atmos. Chem. Phys., 11, 9303-9322, https://doi.org/10.5194/acp-11-9303-2011, 2011.

English, J. M., Toon, O. B., and Mills, M. J.: Microphysical simulations of large volcanic eruptions: Pinatubo and Toba, J. Geophys. Res.-Atmos., 118, 1880-1895, https://doi.org/10.1002/jgrd.50196, 2013.

ESPRI Data Centre: Balloon data for STAC, available at: https:// cds-espri.ipsl.upmc.fr (last access: 2 March 2018), 2017.

Fahey, D. W., Kawa, S. R., Woodbridge, E. L., Tin, P., Wilson, J. C., Jonsson, H. H., Dye, J. E., Baumgardner, D., Borrmann, S., Toohey, D. W., Avallone, L. M., Proffitt, M. H., Margitan, J., Loewenstein, M., Podolske, J. R., Salawitch, R. J., Wofsy, S. C., Ko, M. K. W., Anderson, D. E., Schoeber, M. R., and Chan, K. R.: In situ measurements constraining the role of sulphate aerosols in mid-latitude ozone depletion, Nature, 363, 509-514, https://doi.org/10.1038/363509a0, 1993.

Fromm, M., Kablick, G., Nedoluha, G., Carboni, E., Grainger, R., Campbell, J., and Lewis, J.: Correcting the record of volcanic stratospheric aerosol impact: Nabro and Sarychev Peak, J. Geophys. Res.-Atmos., 119, 10343-10364, https://doi.org/10.1002/2014JD021507, 2014.

Granier, C., Bessagnet, B., Bond, T., D’Angiola, A., van der Gon, H. D., Frost, G. J., Heil, A., Kaiser, J. W., Kinne, S., Klimont, Z., Kloster, S., Lamarque, J.-F., Liousse, C., Masui, T., Meleux, F., Mieville, A., Ohara, T., Raut, J.-C., Riahi, K., Schultz, M. G., Smith, S. J., Thompson, A., van Aardenne, J., van der Werf, G. R., and van Vuuren, D. P.: Evolution of anthropogenic and biomass burning emissions of air pollutants at global and regional scales during the 1980-2010 period, Climatic Change, 109, 163-190, https://doi.org/10.1007/s10584011-0154-1, 2011.

Günther, A., Höpfner, M., Sinnhuber, B.-M., Griessbach, S., Deshler, T., von Clarmann, T., and Stiller, G.: MIPAS observations of volcanic sulfate aerosol and sulfur dioxide in the stratosphere, Atmos. Chem. Phys., 18, 1217-1239, https://doi.org/10.5194/acp-18-1217-2018, 2018.

Hamill, P., Jensen, E. J., Russell, P. B., and Bauman, J. J.: The life cycle of stratospheric aerosol particles, B. Am. Meteorol. Soc., 78, 1395-1410, https://doi.org/10.1175/15200477(1997)078<1395:TLCOSA >2.0.CO;2, 1997.
Haywood, J. M., Jones, A., Clarisse, L., Bourassa, A. E., Barnes, J., Telford, P., Bellouin, N., Boucher, O., Agnew, P., Clerbaux, C., Coheur, P.-F., Degenstein, D., and Braesicke, P.: Observations of the eruption of the Sarychev volcano and simulations using the HadGEM2 climate model, J. Geophys. Res., 115, 1-18, https://doi.org/10.1029/2010JD014447, 2010.

Jégou, F., Berthet, G., Brogniez, C., Renard, J.-B., François, P., Haywood, J. M., Jones, A., Bourgeois, Q., Lurton, T., Auriol, F., Godin-Beekmann, S., Guimbaud, C., Krysztofiak, G., Gaubicher, B., Chartier, M., Clarisse, L., Clerbaux, C., Balois, J. Y., Verwaerde, C., and Daugeron, D.: Stratospheric aerosols from the Sarychev volcano eruption in the 2009 Arctic summer, Atmos. Chem. Phys., 13, 6533-6552, https://doi.org/10.5194/acp13-6533-2013, 2013.

Kettle, A. J., Kuhn, U., Von Hobe, M., Kesselmeier, J., and Andreae, M. O.: Global budget of atmospheric carbonyl sulfide: Temporal and spatial variations of the dominant sources and sinks, J. Geophys. Res.-Atmos., 107, https://doi.org/10.1029/2002JD002187, 2002.

Kravitz, B., Robock, A., and Bourassa, A. E.: Negligible climatic effects from the 2008 Okmok and Kasatochi volcanic eruptions, J. Geophys. Res.-Atmos., 115, 1-16, https://doi.org/10.1029/2009JD013525, 2010.

Kravitz, B., Robock, A., Bourassa, A. E., Deshler, T., Wu, D., Mattis, I., Finger, F., Hoffmann, A., Ritter, C., Bitar, L., Duck, T. J., and Barnes, J. E.: Simulation and observations of stratospheric aerosols from the 2009 Sarychev volcanic eruption, J. Geophys. Res., 116, 1-24, https://doi.org/10.1029/2010JD015501, 2011.

Lamarque, J.-F., Bond, T. C., Eyring, V., Granier, C., Heil, A., Klimont, Z., Lee, D., Liousse, C., Mieville, A., Owen, B., Schultz, M. G., Shindell, D., Smith, S. J., Stehfest, E., Van Aardenne, J., Cooper, O. R., Kainuma, M., Mahowald, N., McConnell, J. R., Naik, V., Riahi, K., and van Vuuren, D. P.: Historical (1850-2000) gridded anthropogenic and biomass burning emissions of reactive gases and aerosols: methodology and application, Atmos. Chem. Phys., 10, 7017-7039, https://doi.org/10.5194/acp-10-7017-2010, 2010.

Levin, B. W., Rybin, A. V., Prytkov, A. S., Chibisova, M. V., Kogan, M. G., Steblov, G. M., and Frolov, D. I.: Monitoring of the eruption of the Sarychev Peak volcano in Matua Island in 2009 (central Kurile islands), Dokl. Earth Sci., 435, 1507-1510, https://doi.org/10.1134/S1028334X10110218, 2010.

Llewellyn, E. J., Lloyd, N. D., Degenstein, D. A., Gattinger, R. L., Petelina, S. V., Bourassa, A. E., Wiensz, J. T., Ivanov, E. V., McDade, I. C., Solheim, B. H., McConnell, J. C., Haley, C. S., von Savigny, C., Sioris, C. E., McLinden, C. A., Griffioen, E., Kaminski, J., Evans, W. F. J., Puckrin, E., Strong, K., Wehrle, V., Hum, R. H., Kendall, D. J. W., Matsushita, J., Murtagh, D. P., Brohede, S., Stegman, J., Witt, G., Barnes, G., Payne, W. F., Piché, L., Smith, K., Warshaw, G., Deslauniers, D.-L., Marchand, P., Richardson, E. H., King, R. A., Wevers, I., McCreath, W., Kyrölä, E., Oikarinen, L., Leppelmeier, G. W., Auvinen, H., Mégie, G., Hauchecorne, A., Lefèvre, F., de La Noë, J., Ricaud, P., Frisk, U., Sjoberg, F., von Schéele, F., and Nordh, L.: The OSIRIS instrument on the Odin spacecraft, Can. J. Phys., 82, 411-422, https://doi.org/10.1139/p04-005, 2004.

Mankin, M. G., Coffey, M. T., and Goldman, A.: Airborne observations of $\mathrm{SO}_{2}, \mathrm{HCl}$ and $\mathrm{O}_{3}$ in the stratospheric plume of the 
Pinatubo volcano in July 1991, Geophys. Res. Lett., 19, 179_ 182, https://doi.org/10.1029/91GL02942, 1992.

Marsh, D. R., Mills, M. J., Kinnison, D. E., Lamarque, J.-F., Calvo, N., and Polvani, L. M.: Climate change from 1850 to 2005 simulated in CESM1(WACCM), J. Climate, 26, 73727391, https://doi.org/10.1175/JCLI-D-12-00558.1, 2013.

Mattis, I., Siefert, P., Müller, D., Tesche, M., Hiebsch, A., Kanitz, T., Schmidt, J., Finger, F., Wandinger, U., and Ansmann, A.: Volcanic aerosol layers observed with multiwavelength Raman lidar over central Europe in 2008-2009, J. Geophys. Res.-Atmos., 115, 1-9, https://doi.org/10.1029/2009JD013472, 2010.

McCormick, M. P., Thomason, L. W., and Trepte, C. R.: Atmospheric effects of the Mt Pinatubo eruption, Nature, 373, 399404, https://doi.org/10.1038/373399a0, 1995.

Mills, M. J., Schmidt, A., Easter, R., Solomon, S., Kinnison, D. E., Ghan, S. J., Neely III, R. R., Marsh, D. R., Conley, A., Bardeen, C. G., and Gettelman, A.: Global volcanic aerosol properties derived from emissions, 1990-2014, using CESM1(WACCM), J. Geophys. Res.-Atmos., 121, 2332-2348, https://doi.org/10.1002/2015JD024290, 2016.

Murphy, D. M., Froyd, K. D., Schwarz, J. P., and Wilson, J. C.: Observations of the chemical composition of stratospheric aerosol particles, Q. J. Roy. Meteor. Soc., 140, 1269-1278, https://doi.org/10.1002/qj.2213, 2014.

Newhall, C. G. and Self, S.: The volcanic explosivity index (VEI): an estimate of explosive magnitude for historical volcanism, J. Geophys. Res.-Oceans, 87, 1231-1238, https://doi.org/10.1029/JC087iC02p01231, 1982.

Oman, L., Robock, A., Stenchikov, G., Schmidt, G. A., and Ruedy, R.: Climatic response to high-latitude volcanic eruptions, J. Geophys. Res., 110, 103, https://doi.org/10.1029/2004JD005487, 2005.

O’Neill, N. T., Perro, C., Saha, A., Lesins, G., Duck, T. J., Eloranta, E. W., Nott, G. J., Hoffman, A., Karumudi, M. L., Ritter, C., Bourassa, A. E., Abboud, I., Carn, S. A., and Savastiouk, V.: Properties of Sarychev sulphate aerosols over the Arctic, J. Geophys. Res., 117, 203, https://doi.org/10.1029/2011JD016838, 2012.

Ovarlez, J. and Ovarlez, H.: Polar Stratospheric Ozone, in: Proceedings of the Third European Workshop, Air Pollut. Rep., vol. 56, Eur. Comm., Luxembourg, 205-208, 1995.

Portmann, R. W., Solomon, S., Garcia, R. R., Thomason, L. W., Poole, L. R., and McCormick, M. P.: Role of aerosol variations in anthropogenic ozone depletion in the polar regions, J. Geophys. Res.-Atmos., 101, 22991-23006, https://doi.org/10.1029/96JD02608, 1996.

Realmuto, V. J. and Berk, A.: Plume Tracker: Interactive mapping of volcanic sulfur dioxide emissions with high-performance radiative transfer modeling, J. Volcanol. Geoth. Res., 327, 55-69, https://doi.org/10.1016/j.jvolgeores.2016.07.001, 2016.

Renard, J.-B., Berthet, G., Robert, C., Chartier, M., Pirre, M., Brogniez, C., Herman, M., Verwaerde, C., Balois, J.-Y., Ovarlez, J., Ovarlez, H., Crespin, J., and Deshler, T.: Optical and physical properties of stratospheric aerosols from balloon measurements in the visible and near-infrared domains. II. Comparison of extinction, reflectance, polarization, and counting measurements, Appl. Optics, 41, 7540-7549, https://doi.org/10.1364/AO.41.007540, 2002.
Renard, J.-B., Ovarlez, J., Berthet, G., Fussen, D., Vanhellemont, F., Brogniez, C., Hadamcik, E., Chartier, M., and Ovarlez, H.: Optical and physical properties of stratospheric aerosols from balloon measurements in the visible and near-infrared domains. III. Presence of aerosols in the middle stratosphere, Appl. Optics, 44, 4086-4095, https://doi.org/10.1364/AO.44.004086, 2005.

Renard, J.-B., Brogniez, C., Berthet, G., Bourgeois, Q., Gaubicher, B., Chartier, M., Balois, J.-Y., Verwaerde, C., Auriol, F., François, P., Daugeron, D., and Engrand, C.: Vertical distribution of the different types of aerosols in the stratosphere: detection of solid particles and analysis of their spatial variability, J. Geophys. Res.-Atmos., 113, 2156-2202, https://doi.org/10.1029/2008JD010150, 2008.

Renard, J.-B., Berthet, G., Salazar, V., Catoire, V., Tagger, M., Gaubicher, B., and Robert, C.: In situ detection of aerosol layers in the middle stratosphere, Geophys. Res. Lett., 37, L20803, https://doi.org/10.1029/2010GL044307, 2010.

Riahi, K., Rao, S., Krey, V., Cho, C., Chirkov, V., Fischer, G., Kindermann, G., Nakicenovic, N., and Rafaj, P.: RCP 8.5 - a scenario of comparatively high greenhouse gas emissions, Climatic Change, 109, 33-57, https://doi.org/10.1007/s10584-011-0149y, 2011.

Ridley, D. A., Solomon, S., Barnes, J. E., Burlakov, V. D., Deshler, T., Dolgii, S. I., Herber, A. B., Nagai, T., Neely III, R. R., Nevzorov, A. V., Ritter, C., Sakai, T., Santer, B. D., Sato, M., Schmidt, A., Uchino, O., and Vernier, J.-P.: Total volcanic stratospheric aerosol optical depths and implications for global climate change, Geophys. Res. Lett., 41, 7763-7769, https://doi.org/10.1002/2014GL061541, 2014.

Rienecker, M. M., Suarez, M. J., Gelaro, R., Todling, R., Bacmeister, J., Liu, E., Bosilovich, M. G., Schubert, S. D., Takacs, L., Kim, G.-K., Bloom, S., Chen, J., Collins, D., Conaty, A., da Silva, A., Gu, W., Joiner, J., Koster, R. D., Lucchesi, R., Molod, A., Owens, T., Pawson, S., Pegion, P., Redder, C. R., Reichle, R., Robertson, F. R., Ruddick, A. G., Sienkiewicz, M., and Woollen, J.: MERRA: NASA's Modern-Era Retrospective analysis for Research and Applications, J. Climate, 24, 3624-3648, https://doi.org/10.1175/JCLI-D-11-00015.1, 2011.

Robock, A.: Volcanic eruptions and climate, Rev. Geophys., 38, 191-219, https://doi.org/10.1029/1998RG000054, 2000.

Russell, P. B., Livingston, J. M., Dutton, E. G., Pueschel, R. F., Reagan, J. A., DeFoor, T. E., Box, M. A., Allen, D., Pilewskie, P., Herman, B. M., Kinne, S. A., and Hofmann, D. J.: Pinatubo and pre-Pinatubo optical-depth spectra: Mauna Loa measurements, comparisons, inferred particle size distributions, radiative effects, and relationship to lidar data, J. Geophys. Res.-Atmos., 98, 22969-22985, https://doi.org/10.1029/93JD02308, 1993.

Rybin, A., Chibisova, M., Webley, P., Steensen, T., Izbekov, P., Neal, C., and Realmuto, V.: Satellite and ground observations of the June 2009 eruption of Sarychev Peak volcano, Matua Island, Central Kuriles, B. Volcanol., 73, 1377-1392, https://doi.org/10.1007/s00445-011-0481-0, 2011.

Sato, M., Hansen, J. E., McCormick, M. P., and Pollack, J. B.: Stratospheric aerosol optical depths, 18501990, J. Geophys. Res.-Atmos., 98, 22987-22994, https://doi.org/10.1029/93JD02553, 1993.

Schmidt, G. A., Ruedy, R., Hansen, J. E., Aleinov, I., Bell, N., Bauer, M., Bauer, S., Cairns, B., Canuto, V., Cheng, Y., Genio, A. D., Faluvegi, G., Friend, A. D., Hall, T. M., Hu, Y., Kel- 
ley, M., Kiang, N. Y., Koch, D., Lacis, A. A., Lerner, J., Lo, K. K., Miller, R. L., Nazarenko, L., Oinas, V., Perlwitz, J., Perlwitz, J., Rind, D., Romanou, A., Russell, G. L., Sato, M., Shindell, D. T., Stone, P. H., Sun, S., Tausnev, N., Thresher, D., and Yao, M.-S.: Present-day atmospheric simulations using GISS ModelE: Comparison to in situ, satellite, and reanalysis data, J. Climate, 19, 153-192, https://doi.org/10.1175/JCLI3612.1, 2006.

Sindelarova, K., Granier, C., Bouarar, I., Guenther, A., Tilmes, S., Stavrakou, T., Müller, J.-F., Kuhn, U., Stefani, P., and Knorr, W.: Global data set of biogenic VOC emissions calculated by the MEGAN model over the last 30 years, Atmos. Chem. Phys., 14, 9317-9341, https://doi.org/10.5194/acp-14-9317-2014, 2014.

Solomon, S.: Stratospheric ozone depletion: A review of concepts and history, Rev. Geophys., 37, 275-316, https://doi.org/10.1029/1999RG900008, 1999.

Solomon, S., Portmann, R. W., Garcia, R. R., Thomason, L. W., Poole, L. R., and McCormick, M. P.: The role of aerosol variations in anthropogenic ozone depletion at northern mid-latitudes, J. Geophys. Res.-Atmos., 101, 6713-6727, https://doi.org/10.1029/95JD03353, 1996.

Solomon, S., Daniel, J. S., Neely III, R. R., Vernier, J.P., Dutton, E. G., and Thomason, L. W.: The persistently variable "background" stratospheric aerosol layer and global climate change, Science, 333, 866-870, https://doi.org/10.1126/science.1206027, 2011.

Sparks, R. S. J.: Forecasting volcanic eruptions, Earth Planet. Sc. Lett., 210, 1-15, https://doi.org/10.1016/S0012-821X(03)001249, 2003.

Stothers, R. B.: Stratospheric aerosol clouds due to very large volcanic eruptions of the early twentieth century: Effective particle sizes and conversion from pyrheliometric to visual optical depth, J. Geophys. Res.-Atmos., 102, 6143-6151, https://doi.org/10.1029/96JD03985, 1997.

Stothers, R. B.: A chronology of annual mean effective radii of stratospheric aerosols from volcanic eruptions during the twentieth century as derived from ground-based spectral extinction measurements, J. Geophys. Res.-Atmos., 106, 32043-32049, https://doi.org/10.1029/2001JD000414, 2001.

Tabazadeh, A. and Turco, R. P.: Stratospheric chlorine injection by volcanic eruptions: $\mathrm{HCl}$ scavenging and implications for ozone, Science, 260, 1082-1086, 1993.

Tabazadeh, A., Toon, O. B., Clegg, S. L., and Hamill, P.: A new parameterization of $\mathrm{H}_{2} \mathrm{SO}_{4} / \mathrm{H}_{2} \mathrm{O}$ aerosol composition: atmospheric implications, Geophys. Res. Lett., 24, 1931-1934, https://doi.org/10.1029/97GL01879, 1997.

Theys, N., De Smedt, I., Gent, J., Danckaert, T., Wang, T., Hendrick, F., Stavrakou, T., Bauduin, S., Clarisse, L., Li, C., Krotkov, N., Brenot, H., and Van Roozendael, M.: Sulfur dioxide vertical column DOAS retrievals from the Ozone Monitoring Instrument: Global observations and comparison to groundbased and satellite data, J. Geophys Res.-Atmos., 120, 2470 2491, https://doi.org/10.1002/2014JD022657, 2015.
Tilmes, S., Müller, R., Salawitch, R. J., Schmidt, U., Webster, C. R., Oelhaf, H., Camy-Peyret, C. C., and Russell III, J. M.: Chemical ozone loss in the Arctic winter 1991-1992, Atmos. Chem. Phys., 8, 1897-1910, https://doi.org/10.5194/acp-8-1897-2008, 2008.

Toon, O. B., Turco, R. P., Westphal, D., Malone, R., and Liu, M.: A multidimensional model for aerosols: Description of computational analogs, J. Atmos. Sci., 45, 2123-2144, https://doi.org/10.1175/15200469(1988)045<2123:AMMFAD>2.0.CO;2, 1988.

Vernier, J.-P., Thomason, L. W., Pommereau, J.-P., Bourassa, A. E., Pelon, J., Garnier, A., Hauchecorne, A., Blanot, L., Trepte, C., Degenstein, D., and Vargas, F.: Major influence of tropical volcanic eruptions on the stratospheric aerosol layer during the last decade, Geophys. Res. Lett., 38, L12807, https://doi.org/10.1029/2011GL047563, 2011.

van de Hulst, H. C. and Twersky, V.: Light scattering by small particles, Phys. Today, 10, 28-30, 1957.

van der Werf, G. R., Randerson, J. T., Giglio, L., Collatz, G. J., Kasibhatla, P. S., and Arellano Jr., A. F.: Interannual variability in global biomass burning emissions from 1997 to 2004, Atmos. Chem. Phys., 6, 3423-3441, https://doi.org/10.5194/acp-6-34232006, 2006.

van der Werf, G. R., Randerson, J. T., Giglio, L., Collatz, G. J., Mu, M., Kasibhatla, P. S., Morton, D. C., DeFries, R. S., Jin, Y., and van Leeuwen, T. T.: Global fire emissions and the contribution of deforestation, savanna, forest, agricultural, and peat fires (1997-2009), Atmos. Chem. Phys., 10, 11707-11735, https://doi.org/10.5194/acp-10-11707-2010, 2010.

von Glasow, R., Bobrowski, N., and Kern, C.: The effects of volcanic eruptions on atmospheric chemistry, Chem. Geol., 263 , 131-142, https://doi.org/10.1016/j.chemgeo.2008.08.020, 2009.

Weisenstein, D. K., Yue, G. K., Ko, M. K. W., Sze, N.-D., Rodriguez, J. M., and Scott, C. J.: A two-dimensional model of sulfur species and aerosols, J. Geophys. Res., 102, 13019-13035, https://doi.org/10.1029/97JD00901, 1997.

Wu, X., Griessbach, S., and Hoffmann, L.: Equatorward dispersion of a high-latitude volcanic plume and its relation to the Asian summer monsoon: a case study of the Sarychev eruption in 2009, Atmos. Chem. Phys., 17, 13439-13455, https://doi.org/10.5194/acp-17-13439-2017, 2017.

Wunderlich, F. and Mitchell, D. M.: Revisiting the observed surface climate response to large volcanic eruptions, Atmos. Chem. Phys., 17, 485-499, https://doi.org/10.5194/acp-17-485-2017, 2017. 